\title{
1 Histidine-rich protein 2: a new pathogenic factor of Plasmodium \\ 2 falciparum malaria
}

3

4 Takashi Iwasaki ${ }^{12^{*}}$, Mayu Shimoda ${ }^{1}$, Haru Kanayama ${ }^{1}$, Tsuyoshi Kawano ${ }^{1,2}$

$5 \quad{ }^{1}$ Department of Agriculture, Graduate school of sustainability science, ${ }^{2}$ Department of

6 Bioresource Science, Faculty of Agriculture, Tottori University, Tottori 680-8553, Japan

$7 \quad$ *To whom correspondence should be addressed: Takashi Iwasaki: Department of Bioresource

8 Science, Faculty of Agriculture, Tottori University, Tottori 680-8553;

$9 \quad$ Email: itaka@tottori-u.ac.jp

10 Tel: $+81-857-31-5458$

11 Author Contributions: T.I., M.S., and H.K. designed the research; T.I., M.S., and H.K.

12 performed the research; T.I., M.S., H.K., and T.K. analyzed the data; and T.I., M.S., and T.K.

13 wrote the paper.

14 Competing Interest Statement: The authors declare no competing interest.

15 Classification: Major classification, Biological Sciences; minor classification, Biochemistry.

16 Keywords: malaria, histidine-rich protein, cell penetration, cytotoxicity, calcium 


\section{Abstract}

Plasmodium falciparum causes serious malaria symptoms; when this protozoan parasite infects human erythrocytes, it produces and secretes large amounts of histidine-rich protein 2 (PfHRP2) into human blood. Thus, PfHRP2 is a well-known diagnostic marker for malaria infection. Here, however, we also identified PfHRP2 as a pathogenic factor produced by $P$. falciparum. PfHRP2 showed cell penetration and cytotoxicity against various human cells. In particular, PfHRP2 showed significant cytotoxicity over 5 days at the same concentration as in $P$. falciparum-infected patients' blood (90-100 nM). This result is consistent with the mortality rate of $P$. falciparum malaria, which increases rapidly in untreated cases for 3-7 days. In addition, the cell penetration and cytotoxicity of PfHRP2 increased 2.5- and 2.6-fold, respectively, in the absence of serum, which suggests that low serum protein concentrations (occurring during malnutrition, for example) increase the risk of adverse effects from PfHRP2 (consistent with malnutrition increasing the lethality of malaria infection). We also showed that PfHRP2 bound to $\mathrm{Ca}^{2+}$ ions, localized to intracellular lysosomes, increased lysosomal $\mathrm{Ca}^{2+}$ levels, and inhibited the basal level of autophagy by inhibiting autolysosome formation. Furthermore, the $\mathrm{Ca}^{2+}$-dependent cytotoxicity of PfHRP2 was suppressed by the metal ion chelator ethylenediaminetetraacetic acid (EDTA). In summary, our findings suggest that PfHRP2 acts as a pathogenic factor in $P$. falciparum-infected patients and is associated with the exacerbation of malaria. Furthermore, EDTA is a promising candidate as a therapeutic agent for the suppression of PfHRP2 pathogenicity. Overall, this study provides new insights into $P$. falciparum malaria pathogenesis and treatment.

\section{Introduction}

The cell membrane acts as a physical barrier that limits the traffic of hydrophilic biomolecules inside and outside of the cell. In particular, typical hydrophilic biomolecules, such as peptides and proteins, are tightly controlled in terms of intracellular and extracellular localization. However, certain peptides and proteins are selectively taken up by the cell via endocytosis. In our previous studies, we reported a new cell-penetrating synthetic polyhistidine peptide consisting of only 16 histidine residues (1) that is efficiently internalized to various human cells. We also reported that nonmembrane permeable proteins, such as green fluorescent protein (GFP) and the hydrolytic enzyme a-galactosidase A (GLA), fused to the polyhistidine peptide by covalent or noncovalent bonds are similarly internalized to human cells (2). These reports indicate that the artificial histidinerich sequences in the proteins significantly increase their membrane permeability. This suggests the possibility that natural histidine-rich proteins may also permeate the cell membrane to become internalized into human cells.

By searching for natural histidine-rich proteins via Protein BLAST (https://blast.ncbi.nlm.nih.gov/Blast.cgi?PAGE=Proteins), we identified histidine-rich protein 2 (PfHRP2) from the protozoan parasite Plasmodium falciparum. The mature PfHRP2 protein 
54 produced by $P$. falciparum consists of 278 amino acid residues with 99 histidine amino acids (35.6\%

55 of the total amino acids) (Fig. 1A) (3, 4). Plasmodium falciparum malaria is an infectious disease in

56 which the pathogenic Plasmodium protozoa are introduced into the human bloodstream through

57 the bite of a female Anopheles mosquito (5). Plasmodium falciparum infects human erythrocytes

58 and induces potentially fatal exacerbation of symptoms including encephalopathy, renal failure,

59 liver disorders, pulmonary edema, severe anemia, metabolic acidosis, hypoglycemia, and black

60 water fever (6). Worldwide, five types of Plasmodium species (Plasmodium vivax, Plasmodium

61 malariae, Plasmodium ovale, Plasmodium knowlesi, and $P$. falciparum) infect 229 million people a

62 year resulting in 409,000 deaths; however, $P$. falciparum is the deadliest parasite, accounting for

63 nearly $99 \%$ of cases in Africa and $94 \%$ of all malaria cases in $2019(7,8)$. PfHRP2 is produced by

$64 P$. falciparum and secreted into human blood in large amounts when the parasite infects human

65 erythrocytes $(9,10)$. Therefore, PfHRP2 is a well-known diagnostic marker for the detection of $P$.

66 falciparum malaria infection (11). The frequent contact between PfHRP2 and human cells suggests

67 that the former may be internalized into the latter in $P$. falciparum-infected patients.

68 In the present study, we examined the possibility of cell penetration by PfHRP2 in human cells; as 69 expected, recombinant PfHRP2 showed significant cell penetration abilities in various human cells.

70 This finding represents a novel phenomenon that had yet to be reported until now. Furthermore,

71 our experiments showed that PfHRP2 is cytotoxic: it inhibited basal-level autophagy after

72 penetration into human cells. Under the same concentration as that in the $P$. falciparum-infected

73 blood of patients (90-100 nM) (12), PfHRP2 showed significant cytotoxicity, which strongly

74 suggests that PfHRP2 cytotoxicity occurs in nature. Further investigations showed that $\mathrm{Ca}^{2+}$ ions

75 are important factors in the cytotoxicity of PfHRP2; moreover, PfHRP2 cytotoxicity was suppressed

76 by a metal ion chelator, ethylenediaminetetraacetic acid (EDTA), which is an approved and

77 inexpensive drug used to treat metal ion-associated diseases. Collectively, the results of this study

78 show for the first time that PfHRP2 is a pathogenic factor involved in the severity of $P$. falciparum

79 malaria and they provide new insights into the treatment of $P$. falciparum malaria via a method that

80 can neutralize PfHRP2 pathogenicity.

81

\section{Results}

83 Cell Penetration by PfHRP2. Recombinant PfHRP2 was expressed in Escherichia coli with a C-

84 terminal FLAG tag (SI Appendix, Fig. S1) and purified using anti-FLAG antibody-immobilized affinity

85 resin (Fig. 1B). Of note, PfHRP2 was detected not only by anti-PfHRP2 and anti-FLAG antibodies

86 but also by anti-His-tag antibody that binds to six consecutive histidine residues. This finding

87 indicates that PfHRP2 has consecutive histidine sequences in its primary structure. In our previous

88 study, we showed that polyhistidine peptide-fusion proteins efficiently penetrate the cell membrane

89 of the human fibrosarcoma HT1080 cell line (1). Thus, in the present study, we attempted to verify

90 the cell penetration of PfHRP2 in the same HT1080 cells. As expected, flow cytometric analysis 
showed that fluorescein-labeled PfHRP2 (Fluo-PfHRP2) was internalized into HT1080 cells within a brief period ( $3 \mathrm{~h}$ ) (Fig. 1C). The efficient cellular uptake of PfHRP2 could be explained by the presence of consecutive histidine sequences detected by the anti-His-tag antibody. In contrast, fluorescein-labeled bovine serum albumin, used as a negative control, showed no cell penetration. A lactic dehydrogenase (LDH) leakage assay showed no LDH leakages from the HT1080 cells treated with PfHRP2 (Fig. 1D). Confocal laser scanning microscopy (CLSM) also showed the obvious cellular uptake of Fluo-PfHRP2 in HT1080 cells (Fig. 1E). Thus, we demonstrated that PfHRP2 passes across the cell membrane without causing cellular membrane damage.

Cell-penetrating Mode of PfHRP2 in Human Fibrosarcoma HT1080 cells. To further investigate the cell-penetrating action of PfHRP2 within the observed 3-h period, the effects of $\mathrm{pH}$, temperature, serum, and protein concentration were examined in Fluo-PfHRP2 cellular uptake in HT1080 cells. Cell penetration of Fluo-PfHRP2 increased when PfHRP2 had a positive charge in weak acidic $\mathrm{pH}$ conditions ( $\mathrm{pH}$ 5.8-6.8) (Fig. 2A). This indicates that a positive charge may be an important factor for PfHRP2 cell penetration. When assessing the effects of temperature, the cell penetration of Fluo-PfHRP2 was inhibited at $30^{\circ} \mathrm{C}$ or $20^{\circ} \mathrm{C}$ compared with cell penetration during incubation at $37^{\circ} \mathrm{C}$ (Fig. 2B), suggesting that PfHRP2 cell penetration depends on a temperature-sensitive cellular uptake pathway. Conversely, the cell penetration of Fluo-PfHRP2 was significantly increased with lower concentrations of fetal bovine serum (FBS) (Fig. 2C); thus, PfHRP2 may have been trapped by serum proteins in the presence of FBS. An ultrafiltration assay showed that FluoPfHRP2 efficiently bound to FBS components (Fig. 2D), indicating that PfHRP2 was weakly trapped by serum in the blood, which in turn affected cell penetration of the protein. Furthermore, the cell penetration of Fluo-PfHRP2 increased in a dose-dependent manner (Fig. 2E); however, with higher concentrations of Fluo-PfHRP2 $(>3.5 \mu \mathrm{M})$, penetration into living cells was not detected in flow cytometric analysis due to an increase in cell death. Thus, we conclude that PfHRP2 is cytotoxic against $\mathrm{HT} 1080$ cells at concentrations $\geq 3.5 \mu \mathrm{M}$.

Cytotoxicity of PfHRP2 against HT1080 cells. To assess the cytotoxicity of PfHRP2 against HT1080 cells, we conducted cell viability assays including PfHRP2 under various conditions. Predictably, PfHRP2 showed dose-dependent cytotoxicity at concentrations up to $3.5 \mu \mathrm{M}$ over a short period ( $3 \mathrm{~h}$ ) (Fig. $3 A$ ). Thus, we predicted that PfHRP2 may show cytotoxicity at lower concentrations over a longer exposure period. A low concentration of PfHRP2 (i.e., $1.0 \mu \mathrm{M}$ ) led to cell penetration within $3 \mathrm{~h}$; 1.0- $\mu \mathrm{M}$ PfHRP2 was not cytotoxic over a short period $(3 \mathrm{~h})$ but showed significant cytotoxicity over longer periods (12 and $24 \mathrm{~h}$ ) (Fig. 3B). Thus, PfHRP2 apparently shows cytotoxicity after cell penetration. Furthermore, the cytotoxicity of PfHRP2 at $1.0 \mu \mathrm{M}$ for $24 \mathrm{~h}$ was greatly increased in the absence of FBS (Fig. $3 C$ ), which suggests that in the absence of serum conditions, e.g., during malnutrition, the risk of PfHRP2 cytotoxicity would increase. Because 
128 PfHRP2 exists at concentrations of 30-100 nM in P. falciparum malaria-infected patients' blood

129 (12-15), we also examined the cytotoxicity of PfHRP2 at these native concentrations for several 130 days. Interestingly, at higher native concentrations of PfHRP2 (90-100 nM), the protein was 131 significantly cytotoxic for 5 days (Fig. 3D). Similar PfHRP2 cytotoxicity was also observed over 3 132 days of incubation (SI Appendix, Fig. S2). Therefore, these results show for the first time that 133 PfHRP2 is a slow-acting pathogenic factor produced by $P$. falciparum malaria.

Cell-penetrating and Cytotoxic Domain of PfHRP2. PfHRP2 showed cell penetration and subsequent cytotoxicity in the experiments described above; thus, we attempted to determine the cell-penetrating and cytotoxic domain of the protein. PfHRP2 mainly consists of the repetitive sequence AHHAHHAAD. First, we designed and synthesized AHHAHHAAD ${ }_{1}, \mathrm{AHHAHHAAD}_{2}$, $\mathrm{AHHAHHAAD}_{3}$, and $\mathrm{AHHAHHAAD}_{4}$ peptides consisting of sequences with 1-4 repeats of AHHAHHAAD (SI Appendix, Fig. S3). However, these repetitive AHHAHHAAD peptides lacked cytotoxicity in HT1080 cells at concentrations up to $100 \mu \mathrm{M}$ over 24-h exposures (SI Appendix, Fig. S3). Thus, truncated PfHRP2 lacking multiple AHHAHHAAD sequences, i.e., PfHRP2( $\triangle 1-42)$, $(\Delta 1-108)$, and ( $\Delta 1-204)$, were prepared via an $E$. coli expression system (Fig. $4 A$ ) before their cell penetration and cytotoxicity were determined. Compared with the cell penetration of full-length PfHRP2, all truncated PfHRP2 proteins showed reduced cell penetration (50\% or less) (Fig. 4B). In a cell viability assay, full-length PfHRP2 and PfHRP2(A1-42) had similar cytotoxicities, whereas PfHRP2( $\Delta 1-108)$ and PfHRP2( $\Delta 1-204)$ lacked cytotoxicity (Fig. $4 C)$. These results indicate that the full-length sequence of PfHRP2 is essential for cell penetration with at least the 42-289 amino acid sequence being required for cytotoxicity. Circular dichroism (CD) spectrum measurements showed that both full-length PfHRP2 and PfHRP2( $1-42)$, which had the same level of cytotoxicity, had a CD spectrum with a negative peak near $200 \mathrm{~nm}$ that is indicative of a random coil secondary structure (Fig. 4D). Conversely, the random coil secondary structure was not observed in PfHRP2( $1-108)$ and PfHRP2( $1-204)$, which lacked cytotoxicity. Thus, the random coil secondary structure seems to be vital for the cytotoxicity of PfHRP2. Comparing full-length PfHRP2 with high cell-penetrating ability and PfHRP2( $11-42)$ with moderate cell-penetrating ability, it was observed that the latter had a CD

158 structure (Fig. 4D); this difference suggests that the excessive $\alpha$-helix secondary structure inhibits 159 the cell penetration of PfHRP2. membrane damage in the LDH leakage assay (Fig. 1D); thus, we eliminated the necrosis pathway as a candidate mechanism of PfHRP2 cytotoxicity. To identify the mechanism, we first investigated 
164 the possibility that PfHRP2 kills human cells via apoptosis. However, the human fibrosarcoma 165 HT1080 cells treated with PfHRP2 showed no morphological changes (SI Appendix, Fig. S4A). An 166 apoptosis detection assay, the Annexin V assay, also indicated that PfHRP2 did not induce 167 phosphatidylserine exposure, which is a known apoptosis marker (SI Appendix, Fig. S4B). Thus, 168 we examined the possibility that PfHRP2 induces autophagy-associated cytotoxicity. Basal 169 autophagy maintains cell proliferation by degradation of intracellular components and the 170 suppression of basal autophagy has been reported to reduce cell proliferation (16). Our CLSM 171 analysis revealed that PfHRP2 localized to intracellular lysosomes, which are known autophagy172 associated organelles, after cell penetration (Fig. 5A). Interestingly, PfHRP2 inhibited 173 autolysosome formation, an event that is induced by lysosome-autophagosome fusion and is 174 essential for the subsequent autophagy process, in a similar manner to a typical autophagy inhibitor, 175 bafilomycin A1 (Fig. 5B). Furthermore, in cells treated with PfHRP2, the amounts of p62 protein, a 176 metabolite accumulated by autophagy dysfunction, increased in a time-dependent manner (Fig. $1775 \mathrm{C}$ ). These results indicate that PfHRP2 is internalized into lysosomes and suppresses basal 178 autophagy by disturbing autolysosome formation (i.e., lysosome-autophagosome fusion) in the 179 cells, similar to bafilomycin A1 (Fig. 5D). an attempt to prevent PfHRP2 pathogenicity, we searched for a potential inhibitor against the protein. First, we assessed the repetitive AHHAHHAAD peptides consisting of partial sequences in

184 PfHRP2 to test whether repetitive AHHAHHAAD peptides show competitive inhibition of pathogenic 185 PfHRP2. However, all repetitive AHHAHHAAD peptides lacked inhibitory effects on PfHRP2 186 cytotoxicity in HT1080 cells (SI Appendix, Fig. S3). Anti-PfHRP2 and anti-His tag antibodies also 187 lacked competitive inhibition in terms of PfHRP2 cell penetration and cytotoxicity (SI Appendix, Fig. 188 S5). Interestingly, however, the metal ion chelator EDTA and ethylene glycol tetraacetic acid 189 (EGTA) significantly inhibited the cytotoxicity of PfHRP2 (Fig 6A). Conversely, neither EDTA nor 190 EGTA inhibited the cell penetration ability of PfHRP2 (SI Appendix, Fig. S6). EDTA is known as a chelator for various divalent metal ions whereas EGTA is a $\mathrm{Ca}^{2+}$-specific chelator. This result suggests that $\mathrm{Ca}^{2+}$ ions are essential for the cytotoxicity of PfHRP2 but not its cell penetration. Thus, the relationship between $\mathrm{Ca}^{2+}$ ions and PfHRP2 pathogenicity was determined. A metal ion detection assay showed that $\mathrm{Ca}^{2+}$ ions bound to PfHRP2 and their binding was inhibited in the presence of EDTA (Fig. 6B). Furthermore, the influence of $\mathrm{Ca}^{2+}$ ions on PfHRP2 cytotoxicity was examined in a $\mathrm{Ca}^{2+}$ concentration-modified medium (SI Appendix, Table S1). Human serum $\mathrm{Ca}^{2+}$ concentrations were $78.1-109.0 \mathrm{mg} / \mathrm{L}$ (17); thus, we used a modified medium containing up to 100 $\mathrm{mg} / \mathrm{L}$ of $\mathrm{Ca}^{2+}$ ions. As expected, $\mathrm{Ca}^{2+}$ ions enhanced PfHRP2 cytotoxicity in a dose-dependent manner (Fig. 6C). However, CD spectrum analysis revealed negligible changes in the secondary structure of PfHRP2 in the presence of $\mathrm{Ca}^{2+}$ or EDTA (SI Appendix, Fig. S7). Therefore, PfHRP2 
201 cytotoxicity can be attributed to factors affected by $\mathrm{Ca}^{2+}$ ions rather than to the protein's secondary 202 structure. As previously mentioned, we showed that PfHRP2 localized to lysosomes (Fig. 5A). 203 Furthermore, lysosomal $\mathrm{Ca}^{2+}$ homeostasis is crucial for cell proliferation (18); thus, we assessed 204 lysosomal $\mathrm{Ca}^{2+}$ levels in cells treated with PfHRP2 and EDTA. As expected, PfHRP2 treatment 205 increased the amount of lysosomal $\mathrm{Ca}^{2+}$ in a dose-dependent manner (Fig. 6D), whereas the 206 PfHRP2-induced increase in lysosomal $\mathrm{Ca}^{2+}$ levels was inhibited by EDTA (Fig. 6E). Generally, $207 \mathrm{Ca}^{2+}$ ions released from lysosomes via a $\mathrm{Ca}^{2+}$-permeable channel promote autophagy (19). 208 However, a recent study reported that lysosomal $\mathrm{Ca}^{2+}$ not only acts as a positive regulator but also 209 functions as a negative regulator in autophagy through the reactivation of mTOR kinase (20). 210 Another study also reported that high $\mathrm{Ca}^{2+}$ concentrations in cytosol inhibit autolysosome formation 211 (21). Given that these studies report $\mathrm{Ca}^{2+}$ ions as negative regulators of autophagy, our findings 212 suggest that PfHRP2 cytotoxicity arises due to an increase in lysosomal $\mathrm{Ca}^{2+}$ (or a subsequent 213 increase in cytosolic $\mathrm{Ca}^{2+}$ ), which acts as a negative regulator of autophagy. Thus, $\mathrm{Ca}^{2+}$ seems to 214 be an essential factor for PfHRP2 cytotoxicity and the pathogenicity of PfHRP2 appears to be 215 caused by increasing lysosomal $\mathrm{Ca}^{2+}$ levels. Furthermore, our findings suggest that $\mathrm{Ca}^{2+}$ ion216 chelators (e.g., EDTA and EGTA) are promising candidates as PfHRP2 inhibitors. Based on our 217 results, we propose a model for the pathogenic and protective mechanisms of PfHRP2 and EDTA, 218 respectively, as shown in Fig. 7.

PfHRP2 Pathogenicity and the Protective Effect of EDTA in Various Human Cells. We demonstrated PfHRP2 pathogenicity and EDTA protective effects in human fibrosarcoma HT1080 cells, but PfHRP2 and EDTA also showed varying degrees of cytotoxicity and protective effects, respectively, in various human cell lines including HT1080 cells (Fig. 8A). PfHRP2 reduced cell proliferation by $87 \%$ in HepG 2 human hepatoma cells, $43 \%$ in HT1080 human fibrosarcoma cells, $34 \%$ in MKN74 human gastric cancer cells, $29 \%$ in Caco-2 human colon carcinoma cells, and 19\% in RERF-LC-Al human squamous lung cancer cells. In contrast, EDTA ameliorated PfHRP2 cytotoxicity by $55 \%$ in HepG2 human hepatoma cells, $41 \%$ in HT1080 human fibrosarcoma cells, and $24 \%$ in MKN74 human gastric cancer cells. However, EDTA was ineffective against PfHRP2 cytotoxicity in RERF-LC-Al human squamous lung cancer cells and Caco-2 human colon carcinoma cells. Thus, the human cell lines used in the present study can be divided into two groups: the EDTA-effective group (HT1080, MKN74, and HepG2 cells) and EDTA-ineffective group (RERF-LC-Al and Caco-2 cells). To understand the underlying reason for differences in PfHRP2 cytotoxicity among human cell lines, we determined and compared PfHRP2 cell penetration and basal autophagy levels in the various human cell lines. PfHRP2 showed varying degrees of cell penetration in these cell lines, but the largest amount of cellular uptake was in HT1080 human fibrosarcoma cells (Fig. 8B). Pearson's correlation analysis showed a weak positive correlation (Pearson's correlation coefficient: $r=$ 
238 0.2520) between the cytotoxicity and cell penetration of PfHRP2, but this correlation was not

239 statistically significant $(p=0.6826)$ (Fig. 8C). In contrast, a basal autophagy detection assay, the

240 DAL green assay in which autolysosome formation is measured, showed differing levels of basal

241 autophagy in human cell lines (Fig. 8D), with the HepG2 human hepatoma cells showing the

242 highest levels of basal autophagy. Interestingly, a strong negative correlation (Pearson's correlation

243 coefficient: $r=-0.8555$ ) existed between the viability of cells treated with PfHRP2 and the basal

244 autophagy levels in seven human cell lines (Fig. 8E). Although statistical analysis showed that the

245 correlation between the cytotoxicity of PfHRP2 and basal autophagy was not significant, the strong

246 negative trend was close to statistical significance $(p=0.0645)$. These results suggest that PfHRP2

247 cytotoxicity moderately depends on basal autophagy levels in cells.

\section{Discussion}

250 Histidine-rich sequences increase the cell penetration of proteins into human cells. Previously, we

251 have demonstrated that nonmembrane permeable proteins, e.g., GFP and GLA, are internalized

252 into human cells by artificial fusion of a polyhistidine peptide consisting of only 16 histidine residues

253 (1, 2). Hence, we hypothesized that natural histidine-rich peptides and proteins may also have

254 similar cell membrane permeability to human cells. In the present study, we demonstrated that

255 PfHRP2, a natural histidine-rich protein produced by $P$. falciparum, showed cell penetration and

256 subsequent cytotoxicity in various human cells. Indeed, this is the first report to demonstrate that a

257 natural histidine-rich protein has cell-penetrating abilities and intracellular function in human cells.

258 As PfRFP2 has such properties, it is possible that other natural histidine-rich proteins may also be

259 internalized into human cells to produce intracellular effects. In future research, further assessment

260 of cell penetration properties may lead to the discovery of new functions for natural histidine-rich

261 proteins other than PfHRP2. Other natural histidine-rich proteins of interest include Homo sapiens

262 histidine-rich glycoprotein (HsHRGP). HsHRGP is a secretory protein found in large amounts in

263 human blood (21) and is frequently in contact with human cells. In addition, HsHRGP is known to

264 have multiple functions including involvement in immunity, angiogenesis, coagulation, clearance of

265 apoptotic phagocytes, cell adhesion, migration, angiogenesis, and sepsis (22-25). Hence, new

266 functions of the natural histidine-rich protein related to human health care are expected to be

267 identified by investigating their cell membrane permeation. Although the biomimetic approach has

268 recently become popular for the creation of artificial functional peptides based on natural protein

269 structures (26-30), the present study pioneered a novel "reverse biomimetic approach" to reveal

270 the function of natural proteins based on artificial peptide structures.

271 Here, we also revealed that the cytotoxicity of PfHRP2 arises by inhibiting basal autophagy after

272 cell penetration. In other words, PfHRP2 is a pathogenic factor produced by $P$. falciparum. In

273 particular, PfHRP2 showed significant cytotoxicity over 3-5 days at concentrations typically found

274 in P. falciparum-infected patient's blood (90-100 nM) (12). This result is consistent with clinical 
275 deterioration caused by $P$. falciparum malaria occurring 3-7 days after the onset of fever (6). In

276 addition, the cell penetration and cytotoxicity of PfHRP2 increased 2.5- and 2.6-fold in the absence

277 of serum, respectively. Therefore, low serum protein concentrations, which occur during

278 malnutrition, seem to increase the risk of negative effects from PfHRP2; this finding is consistent

279 with malnutrition increasing the lethality of malaria infection (31-34). We also showed that PfHRP2

280 was highly cytotoxic to human liver cancer-derived HepG2 cells. The basal level of autolysosome

281 activity in liver cells is known to be higher than that in other tissue cells due to active detoxification

282 and degradation (35), which is consistent with the results of our study. Therefore, we infer that

283 HepG2 cells showed higher susceptibility to PfHRP2 pathogenicity and cytotoxicity because of the

284 inhibition of autolysosome formation. Indeed, hepatic dysfunction is typically severe in $P$.

285 falciparum-infected patients (36), which strongly suggests that PfHRP2 plays an important role in

286 the severity of $P$. falciparum malaria. Until now, PfHRP2 has been considered only as a diagnostic

287 marker of $P$. falciparum malaria infection because it is released in high quantities into the patient's

288 bloodstream. Recently, however, it was reported that PfHRP2 perturbs the blood-brain barrier and

289 promotes the movement of $P$. falciparum into the brain $(37,38)$. Thus, PfHRP2 is not only a

290 secretory protein but also a harmful protein produced by $P$. falciparum. Taken together, the studies

291 to date suggest that PfHRP2 plays a major role in the severity of $P$. falciparum malaria and may be

292 an important target molecule for the treatment of this disease.

293 In the present study, we also attempted to elucidate the cytotoxicity mechanism of PfHRP2. We

294 found that it binds to $\mathrm{Ca}^{2+}$ ions and that $\mathrm{Ca}^{2+}$ ions are required for its cytotoxicity. The AHHAHHAAD

295 peptide, a partial sequence of PfHRP2, has previously been identified as a metal-binding peptide

296 (39); thus, $\mathrm{Ca}^{2+}$ is considered an important factor for PfHRP2. Furthermore, the cytotoxicity of

297 PfHRP2 was robust and not entirely neutralized by partial peptides or antibodies. However, EDTA,

298 a common metal ion chelator, effectively suppressed the cytotoxicity of PfHRP2 in some human

299 cell lines. EDTA is already approved as an inexpensive drug for metal ion-associated diseases

300 (40-42); hence, it is expected to be used as a neutralizing agent against PfHRP2 cytotoxicity. In

$3012019,94.0 \%$ of global malaria deaths occurred in African regions without medical resources and

$30299.7 \%$ of these cases were attributed to $P$. falciparum malaria (7). Therefore, EDTA, as an

303 inexpensive and approved drug, has the potential for use as a treatment to neutralize PfHRP2

304 cytotoxicity and minimize the severity of $P$. falciparum malaria. Future in vivo studies will be required

305 to demonstrate the neutralizing effect of EDTA on PfHRP2 cytotoxicity.

306 We found that EDTA was unable to completely suppress PfHRP2 cytotoxicity because of its inability

307 to inhibit the cell penetration of PfHRP2. Unfortunately, in the present study, neither antibodies nor

308 repetitive AHHAHHAAD peptides were able to inhibit the cytotoxicity of PfHRP2. To completely

309 suppress the cytotoxicity of PfHRP2, it will be necessary to identify binding partners against

310 PfHRP2 on the cell membrane surface. If such a binding partner is identified, it may be possible to 
311 develop an inhibitor that completely suppresses the cell penetration of PfHRP2 by inhibiting the

312 binding between PfHRP2 and its binding partner on the cell membrane surface.

313 P. falciparum malaria is known to produce histidine-rich proteins other than PfHRP2, namely

314 PfHRP1 and PfHRP3. PfHRP1 is a knob-associated histidine-rich protein that forms knob-like

315 protrusions on the surface membrane of $P$. falciparum-infected erythrocytes (43). However,

316 PfHRP1 has a lower histidine content (654 amino acid residues with 49 histidine amino acids; $7.5 \%$

317 of the total amino acids) than that of PfHRP2 and it shows low similarity with PfHRP2. In contrast,

318 PfHRP3 is a secretory protein that has high similarity with PfHRP2, and the mature PfHRP3 protein

319 consists of 233 amino acid residues with 76 histidine amino acids (32.6\% of the total amino acids)

320 (44). The structural similarity between PfHRP2 and PfHRP3 leads to cross-reaction of anti-PfHRP2

321 monoclonal antibodies with PfHRP3. Thus, similar to PfHRP2, PfHRP3 may act as a pathogen.

322 Our findings therefore provide possible novel insights into the potential risk of PfHRP3 regarding $P$.

323 falciparum malaria infection.

324 Alternatively, elimination of PfHRP2 from $P$. falciparum-infected patient's blood may also be an 325 effective treatment against $P$. falciparum malaria. Currently, treatment for $P$. falciparum malaria 326 involves the use of artemisinin combination therapy, artemether-lumefantrine, artesunate327 amodiaquine, artesunate-mefloquine, and dihydroartemisinin-piperaquine to eliminate $P$. 328 falciparum from the patient's body (45). However, PfHRP2 is reported to be retained in the whole 329 blood of artesunate-treated patients with malaria at higher levels, even post-parasite clearance (12, 330 46). Our findings indicate that the large amounts of PfHRP2 present in the patient's body are also 331 an equally important target for elimination. Even if $P$. falciparum is eliminated from the patient's 332 body, the persistence of pathogenic PfHRP2 may subsequently induce severe disease. However, 333 if PfHRP2 is efficiently eliminated from the patient's body at the same time as $P$. falciparum, it may 334 be possible to prevent the severe disease of $P$. falciparum malaria.

\section{Materials and methods}

337 Expression and purification of PfHRP2. A recombinant protein expression vector, $\mathrm{pET}-24 \mathrm{~b}(+)$ 338 (Merck, Darmstadt, Germany), was used to express fusion proteins combining PfHRP2 with C339 terminal FLAG tag via E. coli protein expression systems (SI Appendix, Fig. S1). The plasmid was 340 transformed into the E. coli BL21(DE3) strain by a heat-shock procedure. A single transformant 341 colony was inoculated into Luria-Bertani-Kanamycin $(100 \mu \mathrm{g} / \mathrm{mL})$ medium and grown overnight at $34237^{\circ} \mathrm{C}$. The culture was inoculated at $2-5 \mathrm{~mL}$ into fresh medium and grown at $37^{\circ} \mathrm{C}$ until an 343 absorbance of 0.6 was noted at $600 \mathrm{~nm}$ (mid-logarithmic phase). Isopropyl $\beta-D-1$ 344 thiogalactopyranoside was added to the culture medium (final concentration: $0.1 \mathrm{mM}$ ) and PfHRP2 345 expression was induced at $20^{\circ} \mathrm{C}$ for about $3 \mathrm{~h}$ before cell retrieval. The collected $E$. coli cells were 346 homogenized by sonication in 20-mM phosphate buffer ( $\mathrm{pH}$ 7.4) containing 1-mM 347 phenylmethylsulfonyl fluoride and $200-\mathrm{mM}$ sodium chloride. The homogenate was centrifuged at 
12,000 rpm for $20 \mathrm{~min}$. PfHRP2 recombinant protein was purified by anti-FLAG antibodyimmobilized affinity gel (Medical \& Biological Laboratories Co., Ltd., Nagoya, Japan) and the purified PfHRP2 solution was exchanged into $20-\mathrm{mM}$ sodium phosphate $(\mathrm{pH} 7.4)$ by dialysis before being stored at $4^{\circ} \mathrm{C}$.

The purified PfHRP2 was detected by western blotting. The PfHRP2 was transferred onto polyvinylidene fluoride (PVDF) membranes and probed using the anti-FLAG polyclonal antibody (rabbit lgG), anti-PfHRP2 polyclonal antibody (mouse lgG), and anti-His-tag polyclonal antibody (rabbit IgG) as the first antibodies at rates of 1:50,000, 1:7,500, and 1:5,000, respectively. The horseradish peroxidase-labeled anti-rabbit IgG antibody and anti-mouse IgG antibody were used as the second antibodies at rates of $1: 70,000$ and 1:10,000, respectively. A standard western blotting protocol was used.

Peptide purification. The AHHAHHAAD 1 , AHHAHHAAD $2, \mathrm{AHHAHHAAD}_{3}$, and $\mathrm{AHHAHHAAD}_{4}$ peptides were synthesized by solid-phase peptide synthesis and purchased from Biologica (Shanghai, China). All peptides were purified to homogeneity by high-performance liquid chromatography (HPLC) using a Waters 2489 UV/visible detector and 1524 binary pump (Waters, Milford, MA, USA) and a reversed-phase COSMOSIL 5C18-MS-II column (10 mm $\times 250 \mathrm{~mm})$ (Nacalai Tesque, Kyoto, Japan). The column was run for $50 \mathrm{~min}$ at $3 \mathrm{~mL} / \mathrm{min}$ with a linear gradient from $10 \%$ to $60 \%(\mathrm{v} / \mathrm{v})$ acetonitrile in water containing $0.1 \%(\mathrm{v} / \mathrm{v})$ trifluoroacetic acid. The purity of peptides was calculated from peak areas of the HPLC chart, and the final purity of the peptides was $>95 \%$. The molecular masses were analyzed using matrix-assisted laser desorption/ionization time-of-flight mass spectrometry (Auto Flexll Bruker Daltonics, Billerica, USA).

Cell culture. HT1080 human fibrosarcoma cells, HepG2 human hepatoma cells, and RERF-LC-AI human squamous lung cancer cells were cultured in Eagle's minimal essential medium. Conversely, MKN74 human gastric cancer cells were cultured in RPMI1640 medium. All media contained 10\% FBS (v/v), $100-\mu \mathrm{g} / \mathrm{mL}$ streptomycin, $100-$ units/mL penicillin, and $250-\mathrm{ng} / \mathrm{mL}$ amphotericin B. Caco2 human colon carcinoma cells were cultured in Eagle's minimal essential medium containing $20 \%$ FBS (v/v), $100-\mu \mathrm{g} / \mathrm{mL}$ streptomycin, $100-\mathrm{units} / \mathrm{mL}$ penicillin, and $250-\mathrm{ng} / \mathrm{mL}$ amphotericin B. All human cell lines were purchased from the RIKEN BioResource Research Center (Ibaraki, Japan); they were maintained at $37^{\circ} \mathrm{C}$ in a humidified $5 \% \mathrm{CO}_{2}$ incubator and a subculture was performed every 3-4 days.

Labeling of proteins with fluorescein. To observe the cellular uptake of PfHRP2, PfHRP2, and Bovine serum albumin (BSA) were labeled using the fluorescein 5-maleimide (Tokyo Chemical Industry Co., Ltd., Tokyo, Japan). Proteins $(50-100 \mu \mathrm{M})$ in labeling buffer (20-mM sodium phosphate, $150-\mathrm{mM} \mathrm{NaCl}$, and 10-mM EDTA at $\mathrm{pH}$ 7.2) were mixed with 25-fold amounts of 
fluorescein 5-maleimide. The mixtures were shaded and incubated overnight at room temperature. After incubation, fluorescein-labeled proteins were replaced with $20-\mathrm{mM}$ sodium phosphate $(\mathrm{pH}$ $7.2)$ by dialysis.

LDH leakage assay. To determine cellular membrane damage, cultured cells were seeded onto 96-well plates at a density of $1.0 \times 10^{4}$ cells/well to a final volume of $100 \mu \mathrm{L}$ and then incubated for $24 \mathrm{~h}$ at $37^{\circ} \mathrm{C}$ in $5 \% \mathrm{CO}_{2}$. After complete adhesion, the culture media was replaced with media containing $1 \mu \mathrm{M}$ of proteins and incubated for $3 \mathrm{~h}$. The culture media of each well was replaced with fresh media containing Cytotoxicity LDH Assay Kit-WST (Dojindo, Kumamoto, Japan). LDH leakages, as an index of cellular membrane damage, were determined according to the manufacturer's guidelines. The absorbance at $490 \mathrm{~nm}$ was measured using a multi-plate reader (Tecan, Mannedorf, Switzerland).

Cell viability assay. For the cellular cytotoxicity assay, cultured cells were seeded onto 96-well plates at a density of $1.0 \times 10^{4}$ cells/well to a final volume of $100 \mu \mathrm{L}$ and then incubated for $24 \mathrm{~h}$ at $37^{\circ} \mathrm{C}$ in $5 \% \mathrm{CO}_{2}$. After complete adhesion, the culture media was replaced with fresh media containing various concentrations of proteins and incubated for designed periods. After treatment, the culture media of each well was replaced with $100 \mu \mathrm{L}$ of fresh media containing the Cell Counting Kit-8 reaction solution (Dojindo) and incubated for $4 \mathrm{~h}$. The absorbance at $450 \mathrm{~nm}$ was measured using the multi-plate reader described above.

Flow cytometric analysis. Cell penetration of fluorescein-labeled proteins was determined by flow cytometry. The cultured human cells were seeded onto 24-well plates at a density of $1.0 \times 10^{5}$ cells/well to a final volume of $500 \mu \mathrm{L}$ and then incubated for $24 \mathrm{~h}$ at $37^{\circ} \mathrm{C}$ in $5 \% \mathrm{CO}_{2}$. The culture media was then replaced with fresh media containing various concentrations of fluorescein-labeled proteins and incubated for designed periods. Cells were washed three times with phosphatebuffered saline (PBS), detached with $0.05 \%$ trypsin/0.53-mM EDTA, and suspended in $500 \mu \mathrm{L}$ of FACS buffer (PBS pH 7.4 including 2\% FBS). The fluorescence intensity of fluorescein-labeled proteins internalized into cells was measured by flow cytometric analysis with a BD FACSantoll

CLSM observations. Cultured cells were seeded onto a multiwell glass-bottom dish (Matsunami 418 Ind., Osaka, Japan) at a density of $1.0 \times 10^{4}$ cells/well to a final volume of $100 \mu \mathrm{L}$ and incubated for $24 \mathrm{~h}$ at $37^{\circ} \mathrm{C}$ in $5 \% \mathrm{CO}_{2}$. After complete adhesion, the culture media was replaced with media containing $1 \mu \mathrm{M}$ of fluorescein-labeled proteins and incubated for $3 \mathrm{~h}$. The cell penetration of 421 fluorescein-labeled proteins was observed (excitation wavelength: $480 \mathrm{~nm}$; emission wavelength: 
$422530 \mathrm{~nm}$ ) and fluorescence images were obtained using a confocal laser scanning microscope

423 (FluoView; Olympus, Tokyo, Japan).

424 Intracellular localization of Fluo-PfHRP2 was determined using organelle markers. LysoTracker

425 Red (Life Technologies, CA, USA) and Hoechst33342 (Dojindo) were used as organelle markers

426 for lysosomes and nuclei, respectively. HT1080 cells were precultured in a multiwell glass-bottom

427 dish under the same conditions described above and then incubated with 1- $\mu$ M Fluo-PfHRP2 for 3

$428 \mathrm{~h}$ at $37^{\circ} \mathrm{C}$ in $5 \% \mathrm{CO}_{2}$. Subsequently, $500 \mathrm{nM}$ of LysoTracker Red was added to the cells, which

429 were then incubated for $2 \mathrm{~h}$. Hoechst33342 nuclear staining dye was also added to cells for $1 \mathrm{~h}$.

430 Cells were washed three times with PBS and the intracellular localization of Fluo-PfHRP2 was

431 determined using FluoView.

Autolysosome detection. Autolysosome formation was determined using the autolysosome-

434 specific fluorescent probe, DAL Green (Dojindo), by flow cytometry. The cultured human cells were

435 seeded onto 24-well plates at a density of $1.0 \times 10^{5}$ cells/well to a final volume of $500 \mu \mathrm{L}$ and

436 incubated for $24 \mathrm{~h}$ at $37^{\circ} \mathrm{C}$ in $5 \% \mathrm{CO}_{2}$. The culture media was then replaced with fresh media

437 containing DAL green and incubated for $24 \mathrm{~h}$. Cells were washed three times with PBS, detached

438 with $0.05 \%$ trypsin/0.53-mM EDTA, and suspended in $500 \mu \mathrm{L}$ of FACS buffer (PBS pH 7.4 including

$4392 \%$ FBS). The fluorescence intensity of autolysosomes stained by DAL Green was measured by

440 flow cytometric analysis with a BD FACSantoll instrument (Becton, Dickinson and Company).

441 Approximately $10^{4}$ cells were collected per specimen with three replicates.

443 Autophagy detection. The p62 protein, a classical receptor of autophagy and autophagic 444 substrate, was used as a marker to detect autophagy. The HT1080 cells were seeded onto 96-well 445 plates at a density of $1.0 \times 10^{4}$ cells/well to a final volume of $100 \mu \mathrm{L}$ and then incubated for $24 \mathrm{~h}$ at $44637^{\circ} \mathrm{C}$ in $5 \% \mathrm{CO}_{2}$. After complete adhesion, the culture media was replaced with media containing 447 PfHRP2 $(1 \mu \mathrm{M})$ and incubated for designed periods. After treatment, the HT1080 cells were lysed 448 in the lysis buffer (20-mM sodium phosphate, $\mathrm{pH} 7.2 ; 150-\mathrm{mM}$ sodium chloride; $1 \%$ Nonidet $\mathrm{P}-40$; $449 \quad 0.5 \%$ sodium deoxycholate; and $0.1 \%$ SDS) and the p62 protein was detected by western blotting. 450 The lysates were run on an SDS-PAGE, transferred onto a PVDF membrane, and probed using 451 anti-p62 polyclonal antibody (rabbit lgG) and HRP-labeled anti-rabbit IgG antibody at ratios of $4521: 5,000$ and 1:10,000, respectively. Glyceraldehyde 3-phosphate dehydrogenase (GAPDH) was 453 also detected as an internal control using HRP-labeled anti-GAPDH polyclonal antibody (mouse $454 \mathrm{lgG}$ ) at 1:10,000. A standard western blot protocol was used. Autophagy inhibitory effects were 455 calculated as the ratio of $\mathrm{p} 62$ to GAPDH protein levels. Bafilomycin A1 was used as an autophagy 456 inhibitor. 
$458 \mathrm{Ca}^{2+}$ ions binding assay. The binding between PfHRP2 and $\mathrm{Ca}^{2+}$ ions was determined by 459 calorimetric analysis. PfHRP2 $(1 \mu \mathrm{M})$ was incubated in Eagle's minimal essential medium 460 containing $200 \mathrm{mg} / \mathrm{L}$ of $\mathrm{Ca}^{2+}$ ions at $37^{\circ} \mathrm{C}$ for $1 \mathrm{~h}$. PfHRP2 was then purified by anti-FLAG antibody461 immobilized affinity gel (Medical \& Biological Laboratories Co., Ltd); the amounts of $\mathrm{Ca}^{2+}$ ions 462 bound to PfHRP2 were determined using a Metallo Assay LS Trace Metal Assay Kit for calcium 463 (CPZ III; MG Metallogenics, Chiba, Japan) according to the manufacturer's guidelines. The 464 absorbance at $690 \mathrm{~nm}$ was measured using the previously mentioned multi-plate reader.

Lysosomal $\mathrm{Ca}^{2+}$ measurement. Lysosomal $\mathrm{Ca}^{2+}$ levels were determined by flow cytometry using the Cal520-Dextran (MW 10,000) (AAT Bioquest, CA, USA), a lysosomal $\mathrm{Ca}^{2+}$-specific fluorescent indicator. HT1080 cells were seeded onto 96 -well plates at a density of $1.0 \times 10^{4}$ cells/well to a final volume of $100 \mu \mathrm{L}$ and incubated for $24 \mathrm{~h}$ at $37^{\circ} \mathrm{C}$ in $5 \% \mathrm{CO}_{2}$. After complete adhesion, the culture media was replaced with media containing PfHRP2 $(0.1-1.0 \mu \mathrm{M})$ with or without EDTA $(100 \mu \mathrm{M})$ and incubated for $24 \mathrm{~h}$ at $37^{\circ} \mathrm{C}$ in $5.0 \% \mathrm{CO}_{2}$. After treatment, cells were washed with Hanks' Balanced Salt solution (HBSS) (Sigma-Aldrich, MO, USA) and incubated in HBSS containing 1.0 $\mu \mathrm{M}$ of Cal520-Dextran (MW 10,000) for $2 \mathrm{~h}$ at $37^{\circ} \mathrm{C}$ in $5.0 \% \mathrm{CO}_{2}$. Cells were then washed three times with HBSS, detached with $0.05 \%$ trypsin/0.53-mM EDTA, and suspended in $500 \mu \mathrm{L}$ of FACS buffer (PBS pH 7.4 including 2\% FBS). The fluorescence intensity of lysosomal $\mathrm{Ca}^{2+}$ stained by Cal520-Dextran (MW 10,000) was measured via flow cytometric analysis with a BD FACSantoll instrument (Becton, Dickinson and Company). Approximately $10^{4}$ cells were collected per specimen with three replicates.

CD measurement. CD spectra were recorded in the far UV range, from 300 to $190 \mathrm{~nm}$, on a Jasco J-820 CD spectrophotometer with an attached thermal regulator. CD spectra were acquired for recombinant PfHRP2 proteins $(1 \mu \mathrm{M})$ in the buffer $(20 \mathrm{mM}$ sodium phosphate, $\mathrm{pH} 7.4)$ using a 1$\mathrm{mm}$ path length cell at $37^{\circ} \mathrm{C}$. The typical parameters used in recording the spectra were as follows: bandwidth: $2 \mathrm{~nm}$; response time: $0.5 \mathrm{~s}$; and scan speed: $50 \mathrm{~nm} / \mathrm{min}$. Thirty-two scans were collected, the signal of the buffer was subtracted, and the resulting intensities in millidegrees of the proteins were converted to mean residue molar ellipticity (degrees $\mathrm{cm}^{2} \mathrm{~mol}^{-1}$ ).

Statistical analysis. Correlations were determined using Pearson's correlation analysis and data were fit with a linear regression. Differences between the two groups were analyzed by Student's $t$-test with a two-tailed distribution, whereas differences among multiple groups were evaluated by

491 Tukey's test. All statistical analyses were conducted with add-on software for Excel (Excel Statistics 2010; SSRI, Tokyo, Japan). $p$ values $<0.05$ were considered statistically significant.

494 Data Availability. All study data are included in the article and SI Appendix. 


\section{Acknowledgments}

497 This work was supported in part by a grant from the GSK Japan Research Grant 2017 (to T.I.), the

498 Naito Foundation (to T.I.), and JSPS KAKENHI Grant Number JP17K07771 (to T.I.).

\section{References}

1. T. Iwasaki, et al., Cellular uptake and in vivo distribution of polyhistidine peptides. J. Control. Release 210, 115-124 (2015).

2. T. Iwasaki, N. Murakami, T. Kawano, A polylysine-polyhistidine fusion peptide for lysosometargeted protein delivery. Biochem. Biophys. Res. Commun. 533, 905-912 (2020).

3. L. J. Panton, et al., Purification and partial characterization of an unusual protein of Plasmodium falciparum: histidine-rich protein II. Mol. Biochem. Parasitol. 35, 149-160 (1989).

4. M. Rodriguez-del Valle, et al., Detection of antigens and antibodies in the urine of humans with Plasmodium falciparum malaria. J. Clin. Microbiol. 29, 1236-1242 (1991).

5. M. E. Sinka, et al., The dominant Anopheles vectors of human malaria in Africa, Europe and the Middle East: Occurrence data, distribution maps and bionomic précis. Parasites and

6. A. Trampuz, M. Jereb, I. Muzlovic, R. M. Prabhu, Clinical review: Severe malaria. Crit. Care 7, 315-323 (2003).

514 7. World malaria report 2020 (June 8, 2021).

8. M. Al-Awadhi, S. Ahmad, J. Iqbal, Current status and the epidemiology of malaria in the middle east region and beyond. Microorganisms 9, 1-20 (2021).

9. M. E. Parra, C. B. Evans, D. W. Taylor, Identification of Plasmodium falciparum histidine-rich protein 2 in the plasma of humans with malaria. J. Clin. Microbiol. 29, 1629-1634 (1991).

519 10. V. Desakorn, et al., Semi-quantitative measurement of Plasmodium falciparum antigen

520 PfHRP2 in blood and plasma. Trans. R. Soc. Trop. Med. Hyg. 91, 479-483 (1997).

521 11. K. E. Poti, D. J. Sullivan, A. M. Dondorp, C. J. Woodrow, HRP2: Transforming Malaria

522 Diagnosis, but with Caveats. Trends Parasitol. 36, 112-126 (2020). 
523 12. P. A. Ndour, et al., Measuring the Plasmodium falciparum HRP2 protein in blood from artesunate-treated malaria patients predicts post-artesunate delayed hemolysis. Sci. Transl. Med. 9 (2017).

13. C. M. Kifude, et al., Enzyme-linked immunosorbent assay for detection of Plasmodium falciparum histidine-rich protein 2 in blood, plasma, and serum. Clin. Vaccine Immunol. 15, 1012-1018 (2008).

14. G. S. Park, et al., Plasmodium falciparum histidine-rich protein-2 plasma concentrations are higher in retinopathy-negative cerebral malaria than in severe malarial anemia. Open Forum Infect. Dis. 4 (2017).

15. S. Uyoga, et al., Plasma Plasmodium falciparum Histidine-rich protein 2 concentrations in children with malaria infections of differing severity in Kilifi, Kenya. Clin. Infect. Dis. (2020) https:/doi.org/10.1093/cid/ciaa1141 (June 8, 2021).

16. V. O. Kaminskyy, T. Piskunova, I. B. Zborovskaya, E. M. Tchevkina, B. Zhivotovsky, Suppression of basal autophagy reduces lung cancer cell proliferation and enhances caspase-dependent and -independent apoptosis by stimulating ROS formation. Autophagy 8 , 1032-1044 (2012).

17. N. Ishizaka, et al., Serum calcium concentration and carotid artery plaque: a population-

18. D. A. East, M. Campanella, $\mathrm{Ca}^{2+}$ in quality control: An unresolved riddle critical to autophagy and mitophagy. Autophagy 9, 1710-1719 (2013).

19. D. L. Medina, A. Ballabio, Lysosomal calcium regulates autophagy. Autophagy 11, 970-971 (2015).

20. D. L. Medina, "Lysosomal calcium and autophagy" in International Review of Cell and Molecular Biology, (Elsevier Inc., 2021) https:/doi.org/10.1016/bs.ircmb.2021.03.002.

547 21. C. Mauvezin, P. Nagy, G. Juhász, T. P. Neufeld, Autophagosome-lysosome fusion is 548 independent of V-ATPase-mediated acidification. Nat. Commun. 6, 7007 (2015). The Swiss Army knife of mammalian plasma. Blood 117, 2093-2101 (2011).

551 23. R. Simantov, et al., Histidine-rich glycoprotein inhibits the antiangiogenic effect of 552 thrombospondin-1. J. Clin. Invest. 107, 45-52 (2001). 
553

24. M. Blank, Y. Shoenfeld, Histidine-rich glycoprotein modulation of immune/autoimmune, vascular, and coagulation systems. Clin. Rev. Allergy Immunol. 34, 307-312 (2008).

25. H. Wake, Histidine-rich glycoprotein modulates the blood-vascular system in septic condition. Acta Med. Okayama 73, 379-382 (2019).

26. D. T. Haynie, L. Zhang, W. Zhao, J. S. Rudra, Protein-inspired multilayer nanofilms: science, technology and medicine. Nanomedicine Nanotechnology, Biol. Med. 2, 150-157 (2006).

27. Y. Li, X. Liu, X. Dong, L. Zhang, Y. Sun, Biomimetic design of affinity peptide ligand for capsomere of virus-like particle. Langmuir 30, 8500-8508 (2014).

28. W. Du, X. Hu, W. Wei, G. Liang, Intracellular peptide self-assembly: a biomimetic approach for in situ nanodrug preparation. Bioconjug. Chem. 29, 826-837 (2018).

29. R. Surís-Valls, I. K. Voets, Peptidic antifreeze materials: Prospects and challenges. Int. J. Mol. Sci. 20 (2019).

30. Q. Hou, L. Zhang, Biomimetic design of peptide neutralizer of Ebola virus with molecular simulation. Langmuir 36, 1813-1821 (2020).

31. J. S. Edirisinghe, Infections in the malnourished: With special reference to malaria and malnutrition in the tropics. Ann. Trop. Paediatr. 6, 233-237 (1986).

32. E. G. Kasili, Malnutrition and infections as causes of childhood anemia in tropical africa. J. Pediatr. Hematol. Oncol. 12, 375-377 (1990).

33. J. A. Berkley, et al., HIV infection, malnutrition, and invasive bacterial infection among children with severe malaria. Clin. Infect. Dis. 49, 336-343 (2009).

34. K. D. J. Jones, J. A. Berkley, Severe acute malnutrition and infection. Paediatr. Int. Child Health 34, S1-S29 (2014).

35. T. Ueno, M. Komatsu, Autophagy in the liver: Functions in health and disease. Nat. Rev. Gastroenterol. Hepatol. 14, 170-184 (2017).

36. A. Bhalla, V. Suri, V. Singh, Malarial hepatopathy. J. Postgrad. Med. 52, 315-320 (2006).

37. P. Pal, et al., Plasmodium falciparum histidine-rich protein II compromises brain endothelial barriers and may promote cerebral malaria pathogenesis. MBio 7 (2016).

38. P. Pal, et al., Plasmodium falciparum histidine-rich protein II causes vascular leakage and exacerbates experimental cerebral malaria in mice. PLoS One 12 (2017). 
582 39. J. I. B. Janairo, Peptide-Mediated Biomineralization (Springer, 2016)

583 https:/doi.org/10.1007/978-981-10-0858-0 (June 11, 2021).

584 40. P. M. Wax, Current Use of Chelation in American Health Care. J. Med. Toxicol. 9, 303-307

585 (2013).

586 41. T. Born, C. N. Kontoghiorghe, A. Spyrou, A. Kolnagou, G. J. Kontoghiorghes, EDTA chelation 587 reappraisal following new clinical trials and regular use in millions of patients: Review of 588 preliminary findings and risk/benefit assessment. Toxicol. Mech. Methods 23, 11-17 (2013).

589 42. J. A. Drisko, "Chelation Therapy" in Integrative Medicine: Fourth Edition, (Elsevier, 2018), pp. $590 \quad$ 1004-1015.e3.

591 43. J. Gruenberg, D. R. Allred, I. W. Sherman, Scanning electron microscope-analysis of the 592 protrusions (knobs) present on the surface of Plasmodium falciparum-infected erythrocytes.

$593 \quad$ J. Cell Biol. 97, 795-802 (1983).

594 44. E. P. Rock, et al., Comparative analysis of the Plasmodium falciparum histidine-rich proteins 595 HRP-I, HRP-II and HRP-III in malaria parasites of diverse origin. Parasitology 95, 209-227 596 (1987).

597 45. W. G. S. Group, Gametocyte carriage in uncomplicated Plasmodium falciparum malaria 598 following treatment with artemisinin combination therapy: a systematic review and metaanalysis of individual patient data. BMC Med. 14, 79 (2016).

46. K. E. Poti, et al., In vivo compartmental kinetics of Plasmodium falciparum histidine-rich protein II in the blood of humans and in BALB/c mice infected with a transgenic Plasmodium berghei parasite expressing histidine-rich protein II. Malar. J. 18 (2019). 


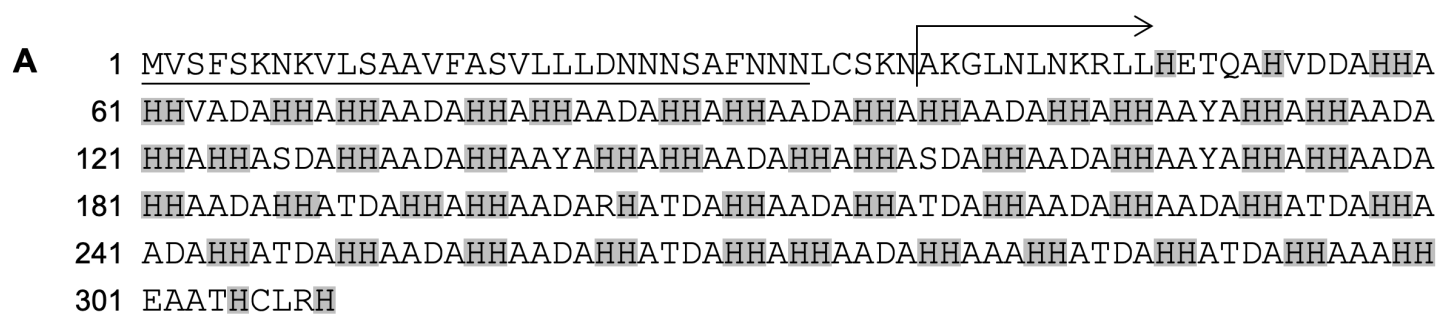

B

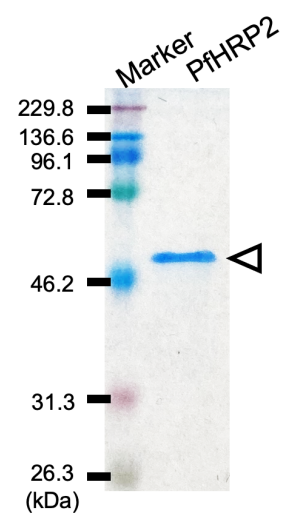

C

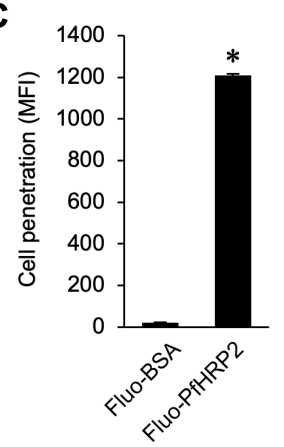

Anti-PfHRP2 antibody

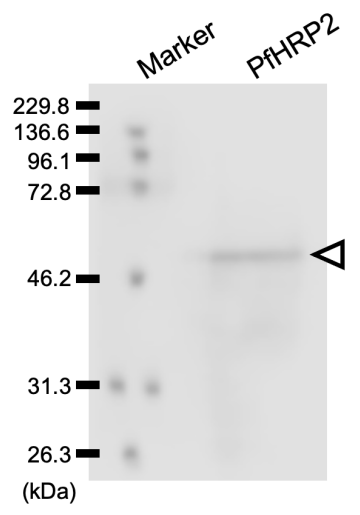

D

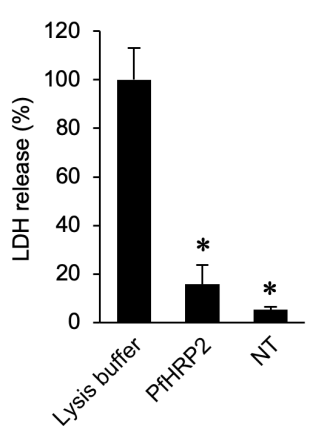

Anti-His-tag antibody
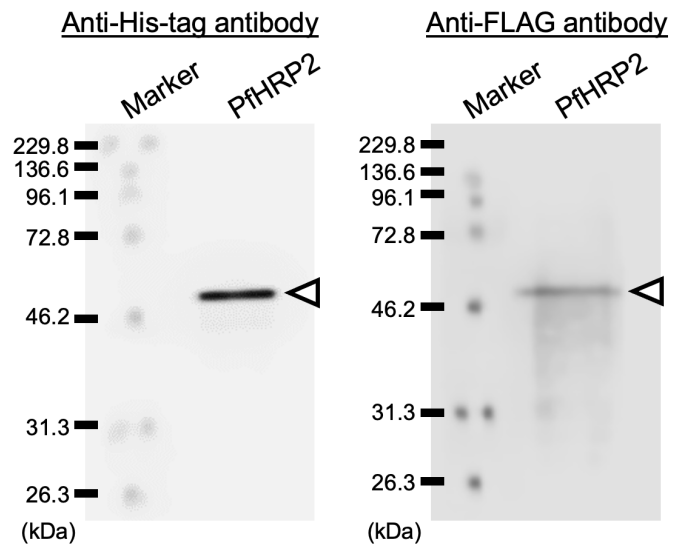

E

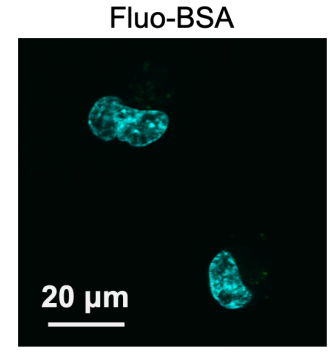

Fluo-PfHRP2

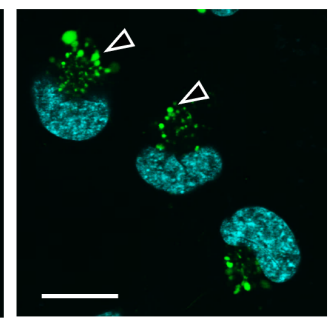

Fig. 1. Preparation of recombinant PfHRP2 and its cellular uptake against human fibrosarcoma HT1080 cells. (A) The amino acid sequence of Plasmodium falciparum histidine-rich protein II 605 (PfHRP2). Underlining and gray boxes indicate the signal sequence and histidine residues, 606 respectively. Arrow indicates initial sequences of recombinant PfHRP2 used in the present study. $(B)$ SDS-PAGE and western blotting images of recombinant PfHRP2. The recombinant PfHRP2 with C-terminal FLAG tag (DYKDDDDK) was expressed in E. coli and purified using an anti-FLAG affinity column. Purified PfHRP2 was confirmed by SDS-PAGE and western blotting using anti- 
610 PfHRP2, anti-His-tag, and anti-FLAG antibodies. (C) Cellular uptake of PfHRP2 in human 611 fibrosarcoma HT1080 cells. The HT1080 cells were treated with fluorescein-labeled PfHRP2 and 612 bovine serum albumin (Fluo-PfHRP2 and Fluo-BSA) at $1 \mu \mathrm{M}$ and $37^{\circ} \mathrm{C}$ for $3 \mathrm{~h}$. Cell penetration of 613 proteins was evaluated by the mean fluorescent intensity (MFI) in the flow cytometric analysis. 614 Means and SD are shown ( $\left.{ }^{*} p<0.05\right)$. (D) Lactate dehydrogenase (LDH) leakage in HT1080 cells. 615 The HT1080 cells were treated with PfHRP2 $(1 \mu \mathrm{M})$ cells at $37^{\circ} \mathrm{C}$ for $3 \mathrm{~h}$ and then $\mathrm{LDH}$ release was 616 determined with a Cytotoxicity LDH Assay Kit-WST according to manufacturer's protocol. NT 617 indicates nontreated cells used as a negative control. Means and SD are shown $\left({ }^{*} p<0.05\right)$. (E) 618 Cellular uptake image of PfHRP2 in HT1080 cells. HT1080 cells were treated with Fluo-PfHRP2 (1 $619 \mu \mathrm{M})$ or Fluo-BSA $(1 \mu \mathrm{M})$ at $37^{\circ} \mathrm{C}$ for $3 \mathrm{~h}$. Cyan fluorescence and arrowheads indicate nuclei stained 620 with Hoechst 33258 and Fluo-PfHRP2 internalized into HT1080 cells, respectively. Scale bars: 20 $621 \mu \mathrm{m}$. 

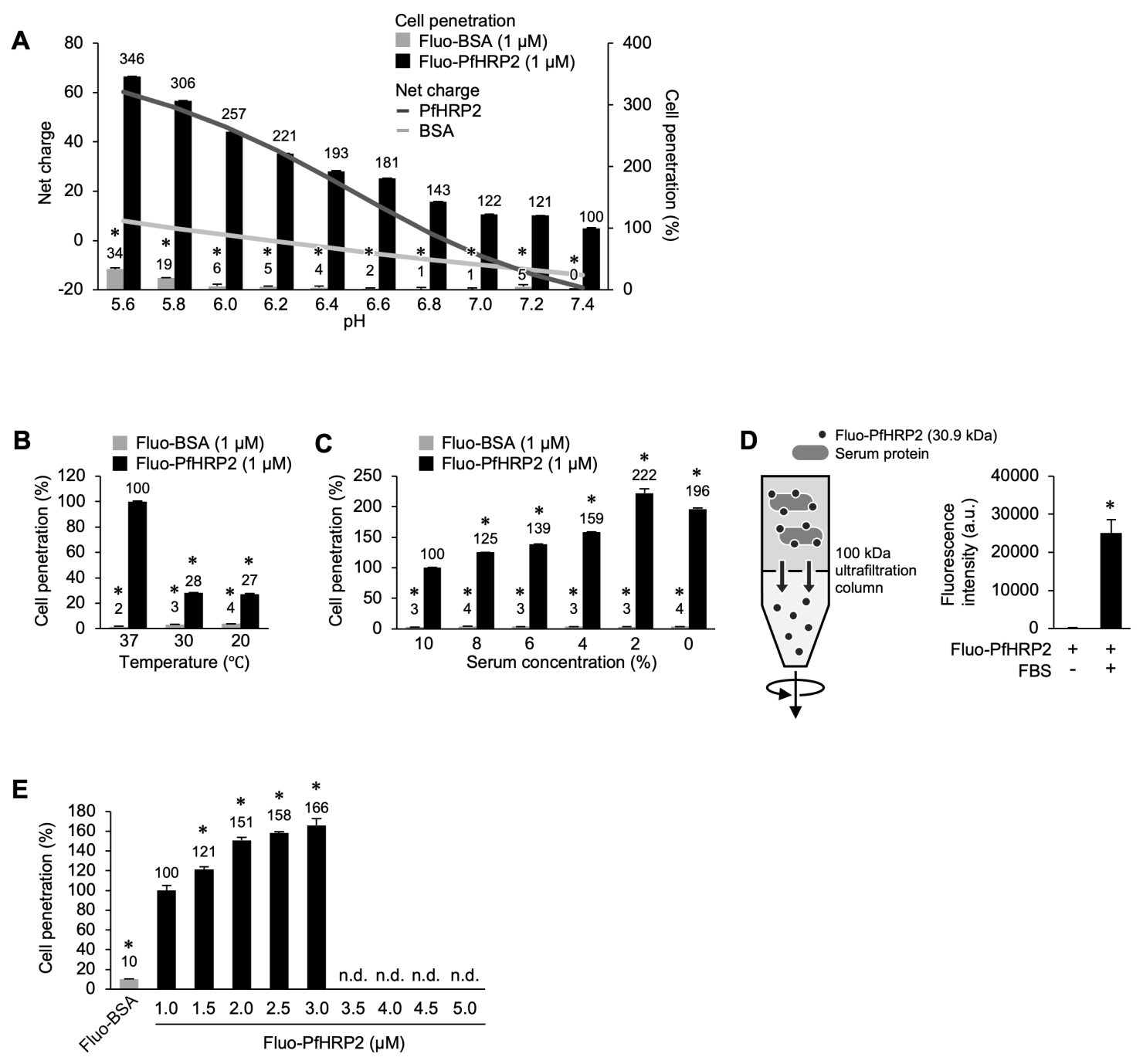

622 Fig. 2. Cellular uptake of PfHRP2 in HT1080 cells. Influences of $(A) \mathrm{pH},(B)$ temperature, and $(C)$ 623 serum concentrations on the cellular uptake of Fluo-PfHRP2 in HT1080 cells. The HT1080 cells 624 were treated with Fluo-PfHRP2 and Fluo-BSA in designed conditions for $3 \mathrm{~h}$. Relative cell penetration of proteins was evaluated by mean fluorescent intensity (MFI) via flow cytometric analysis. $(D)$ Binding of Fluo-PfHRP2 and serum proteins. Fluo-PfHRP2 $(1 \mu \mathrm{M})$ was incubated in $10 \%$ fetal bovine serum (FBS) at $37^{\circ} \mathrm{C}$ for $3 \mathrm{~h}$. Fluo-PfHRP2 $(1 \mu \mathrm{M})$ bound to serum proteins was collected using a $100-\mathrm{kDa}$ ultrafiltration column. The fluorescence intensity of the ultrafiltrated fraction was quantified using a fluorescence microplate reader. $(E)$ Cellular uptake of various concentrations of Fluo-PfHRP2 in HT1080 cells. The HT1080 cells were treated with Fluo-PfHRP2 $(1.0-5.0 \mu \mathrm{M})$ at $37^{\circ} \mathrm{C}$ for $3 \mathrm{~h}$. Relative cell penetration was calculated by MFI via flow cytometric analysis. Means and SD are shown $\left({ }^{*} p<0.05\right)$. n.d. indicates "not determined." 

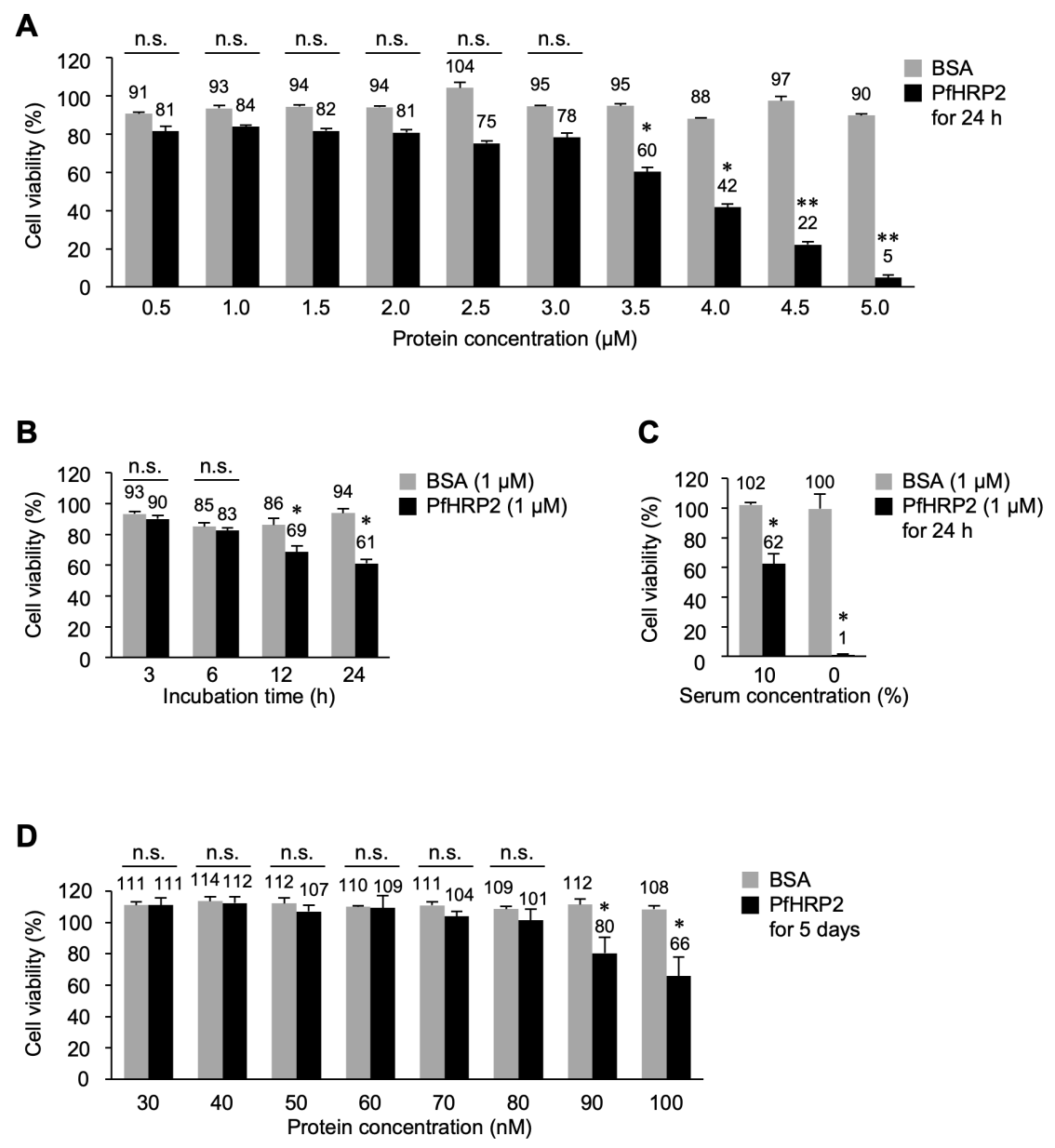

633 Fig. 3. Cytotoxicity of PfHRP2 in HT1080 cells. Influences of $(A)$ protein concentration, $(B)$ 634 incubation time, and $(C)$ serum concentrations on the cytotoxicity of PfHRP2 in HT1080 cells. $635 \mathrm{HT} 1080$ cells were treated with PfHRP2 and BSA in designed conditions at $37^{\circ} \mathrm{C}$. $(D)$ Cytotoxicity 636 of PfHRP2 at native concentrations for 5 days in HT1080 cells. The HT1080 cells were treated with 637 PfHRP2 at native concentrations (30-100 nM) in $P$. falciparum malaria-infected patients' blood 638 (maintained at $37^{\circ} \mathrm{C}$ for 5 days). Relative cell viability was determined using the Cell Counting Kit6398 reaction solution. Means and SD are shown $\left({ }^{*} p<0.05\right.$ and $\left.{ }^{* *} p<0.01\right)$. n.s. indicates a 640 nonsignificant difference. 
bioRxiv preprint doi: https://doi.org/10.1101/2021.11.19.469193; this version posted November 19,2021 . The copyright holder for this preprint (which was not certified by peer review) is the author/funder, who has granted bioRxiv a license to display the preprint in perpetuity. It is made available under aCC-BY-NC-ND 4.0 International license.

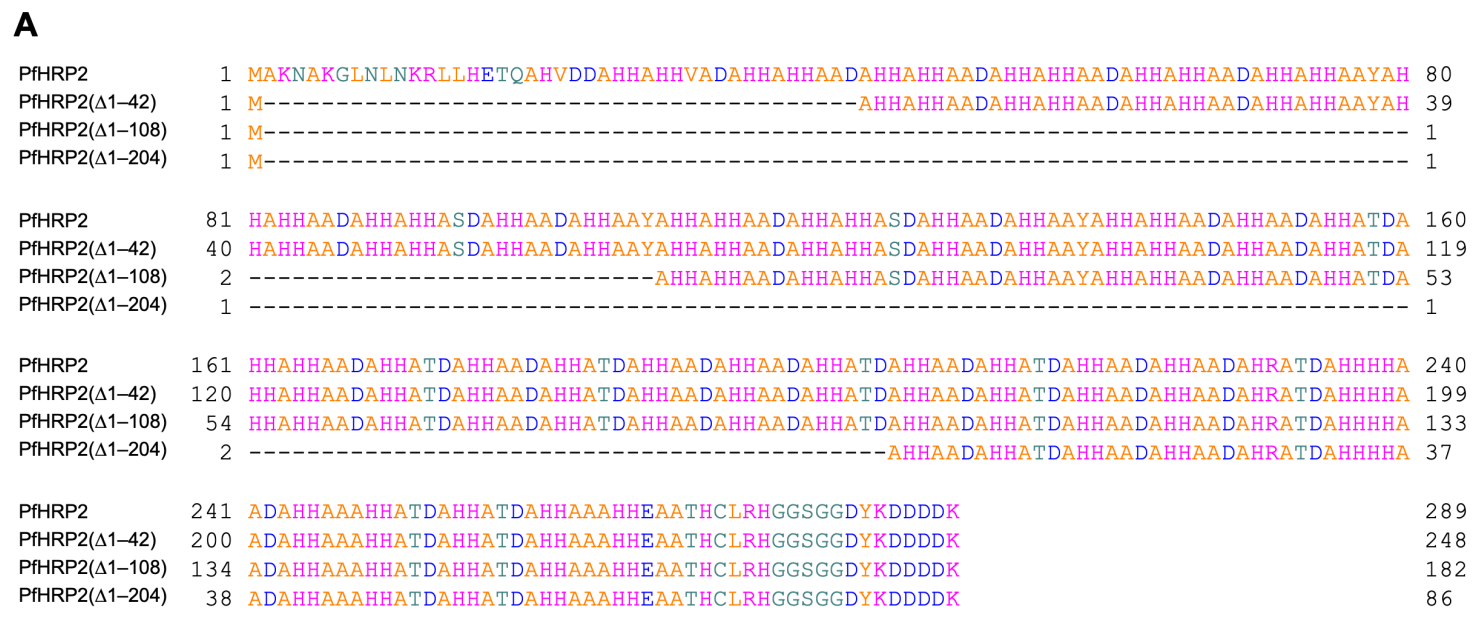

B

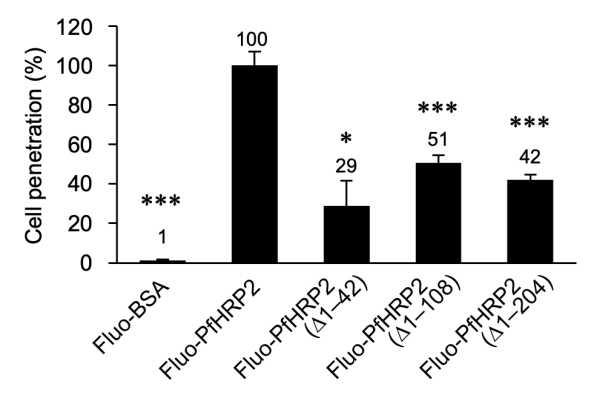

C

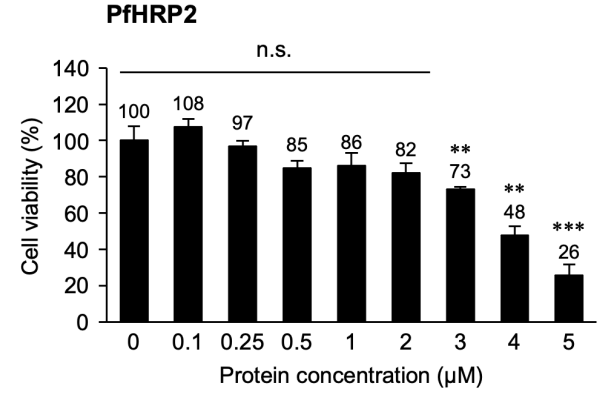

$\operatorname{PfHRP2}(\Delta 1-108)$

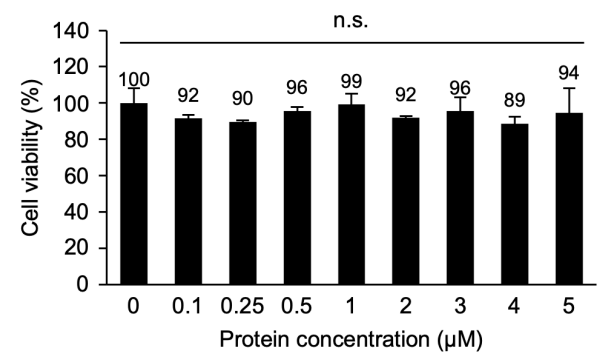

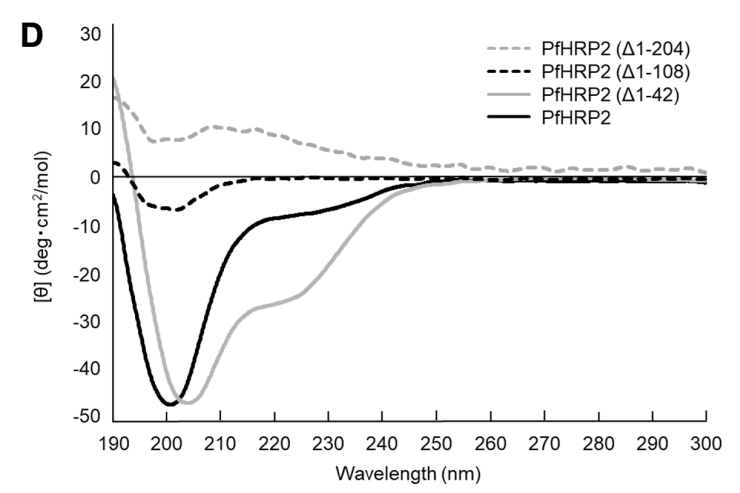

$\operatorname{PfHRP2(\Delta 1-42)}$

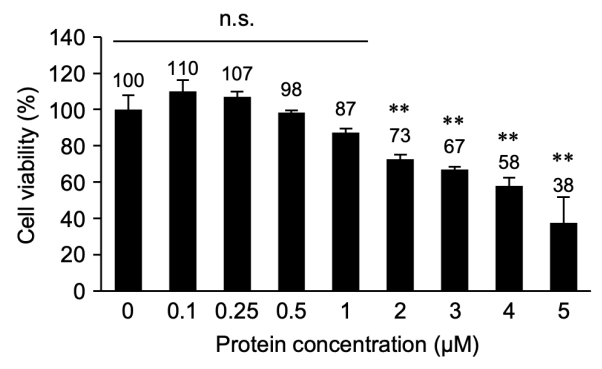

PfHRP2(A1-204)

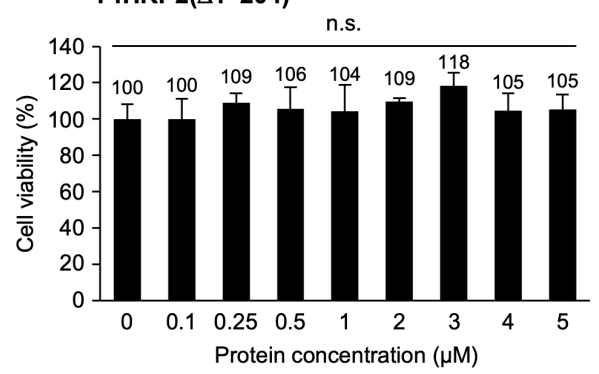

Fig. 4. Cell-penetrating and cytotoxic region of PfHRP2. (A) Amino acid sequences of full-length 
642 and truncated PfHRP2. (B) Comparison between cellular uptake of the full-length and truncated

643 PfHRP2. HT1080 cells were treated with the fluorescein-labeled full-length and truncated PfHRP2

644 at $1 \mu \mathrm{M}$ and $37^{\circ} \mathrm{C}$ for $3 \mathrm{~h}$. Relative cell penetration of proteins was calculated by the MFI in the flow

645 cytometric analysis. Means and SD are shown $\left({ }^{*} p<0.05,{ }^{* *} p<0.01\right.$, and $\left.{ }^{* * *} p<0.001\right)$. (C)

646 Comparison between the cytotoxicity of the full-length and truncated PfHRP2. The HT1080 cells

647 were treated with various concentrations of full-length and truncated PfHRP2 at $37^{\circ} \mathrm{C}$ for $24 \mathrm{~h}$.

648 Relative cell viability was determined using the Cell Counting Kit-8 reaction solution. Means and

$649 \mathrm{SD}$ are shown $\left({ }^{*} p<0.05,{ }^{* *} p<0.01\right.$, and $\left.{ }^{* * *} p<0.001\right)$. (D) Circular dichroism (CD) spectra of the

650 full-length and truncated PfHRP2. The CD spectrum of each protein $(5 \mu \mathrm{M})$ was measured in 20-

$651 \mathrm{mM}$ phosphate buffer $(\mathrm{pH} 7.4)$ using a 1-mm path length cell at $37^{\circ} \mathrm{C}$ on a Jasco J-820 CD

652 spectrophotometer. 
A

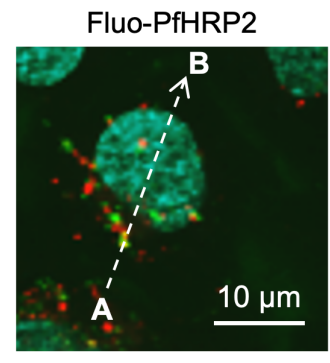

B

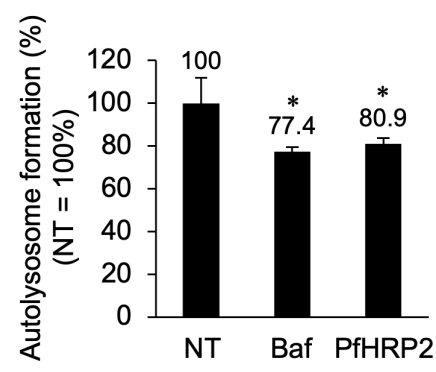

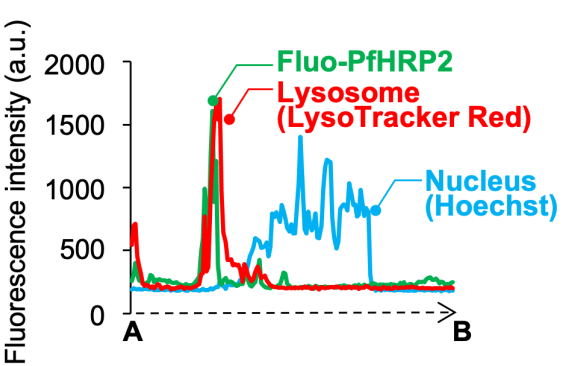

C

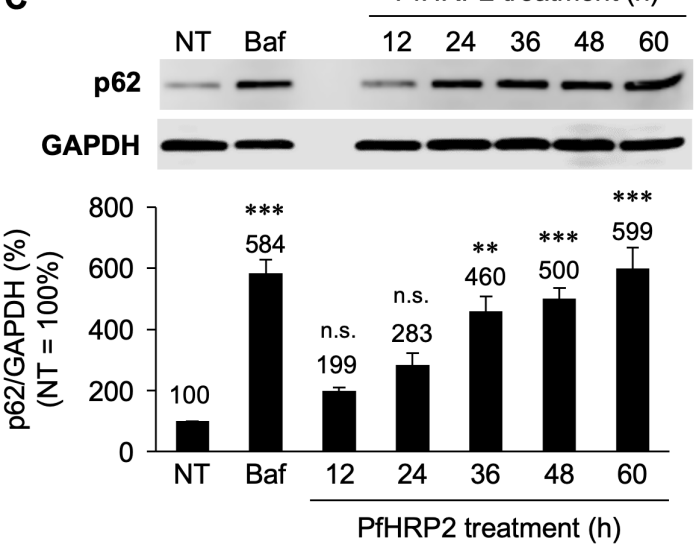

D

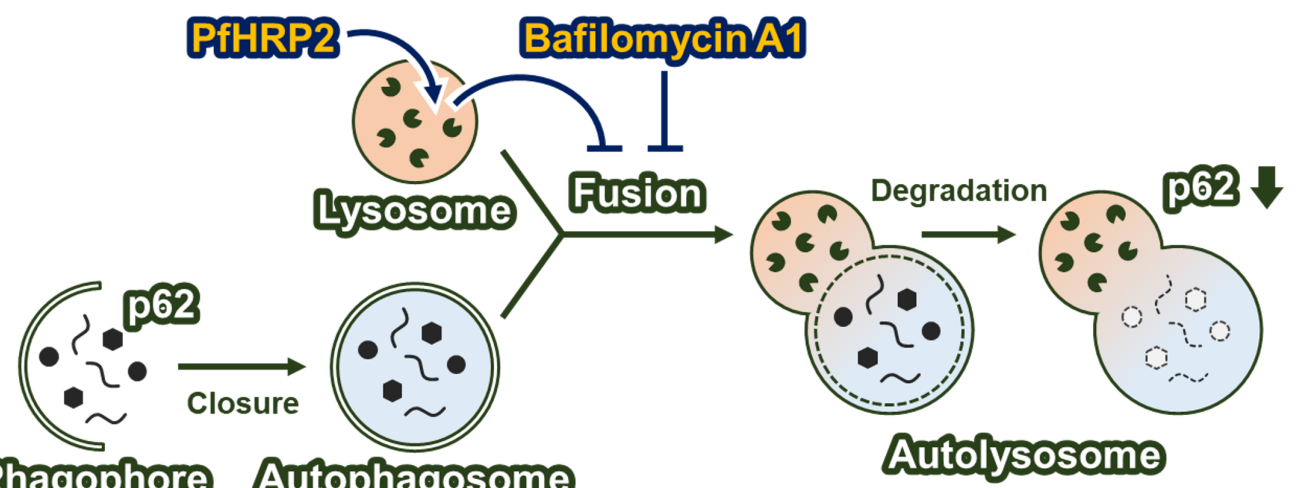

\section{Phagophore Autophagosome}

Autolysosomo

Lysosomal enzyme

p62

$\sim$ Other autophagic cargoes

Fig. 5. Autolysosome dysfunction by PfHRP2 in HT1080 cells. (A) Colocalization of Fluo-PfHRP2 
654 to lysosomes in HT1080 cells. Distribution of the Fluo-PfHRP2, nucleus, and lysosome was 655 quantified by measuring fluorescence intensity in the dotted line areas between A and B. Green, 656 red, and cyan fluorescence indicate Fluo-PfHRP2, endogenous lysosome stained with LysoTracker 657 Red, and nucleus stained with Hoechst 33258, respectively. Scale bar: $10 \mu \mathrm{m}$. (B) Autolysosome 658 formations inhibited by PfHRP2 in HT1080 cells. The HT1080 cells were treated with bafilomycin 659 A1 (Baf; $25 \mathrm{nM})$, a typical inhibitor of autolysosome formation, or PfHRP2 $(1 \mu \mathrm{M})$ at $37^{\circ} \mathrm{C}$ for $12 \mathrm{~h}$. 660 Cellular autolysosomes were stained by the DAL Green autolysosome-specific fluorescent probe 661 and relative autolysosome formation was calculated by MFI in the flow cytometric analysis. (C) 662 Autolysosome dysfunction induced by PfHRP2 in HT1080 cells. The HT1080 cells were treated 663 with bafilomycin A1 (Baf; $100 \mathrm{nM}$ ) for $4 \mathrm{~h}$ or PfHRP2 $(1 \mu \mathrm{M})$ for $12-60 \mathrm{~h}$ at $37^{\circ} \mathrm{C}$, respectively. Cell 664 lysates were prepared from the treated cells, and p62 protein, a metabolite accumulated during 665 autolysosome dysfunction, was detected by western blotting. Relative amounts of p62 protein were 666 calculated by normalizing p62 with glyceraldehyde 3-phosphate dehydrogenase (GAPDH). Means 667 and SD are shown $\left({ }^{*} p<0.05,{ }^{* *} p<0.01\right.$, and $\left.{ }^{* * *} p<0.001\right)$. n.s. indicates a nonsignificant difference. 668 (D) Scheme for PfHRP2 inhibiting cellular proliferation. PfHRP2 is internalized into lysosomes and 669 inhibits autolysosome formation in a similar manner to bafilomycin A1. 
A

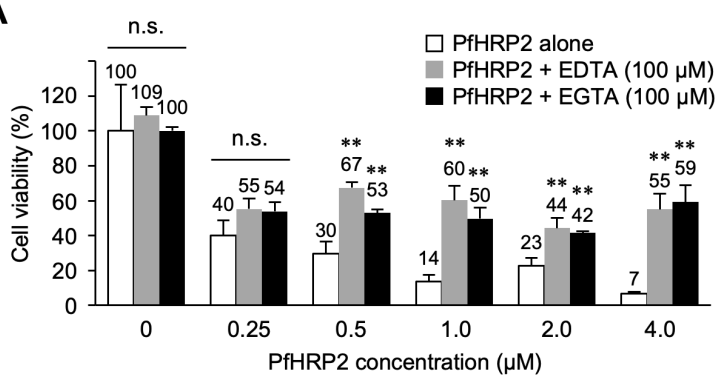

B

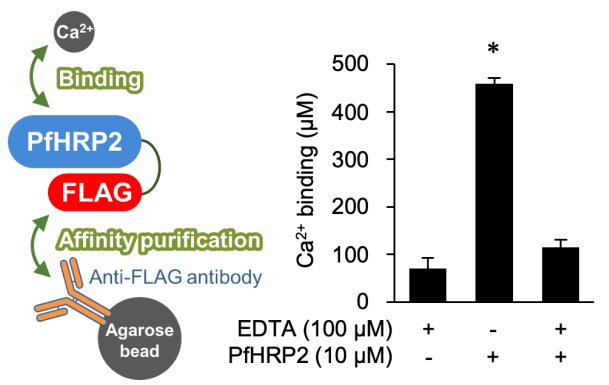

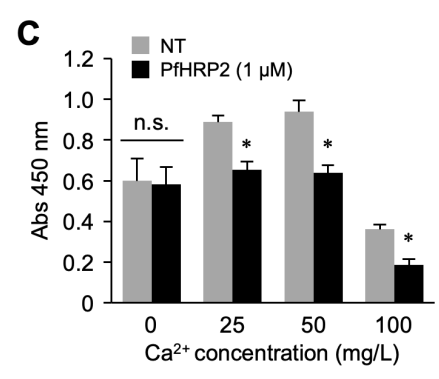

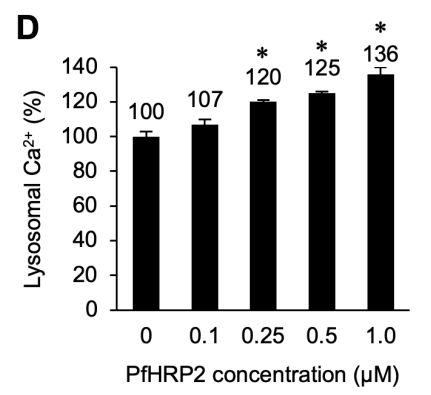

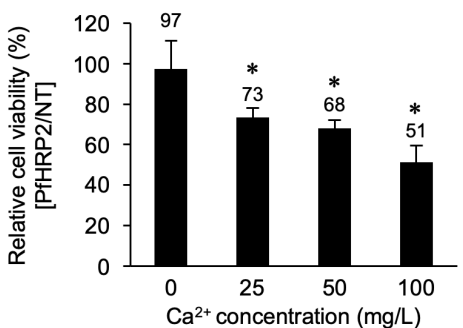

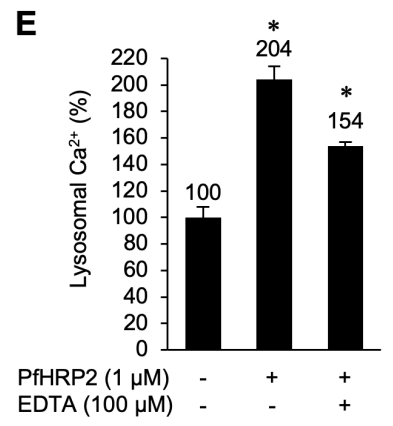

670 Fig. 6. Protective effects of EDTA/EGTA on $\mathrm{Ca}^{2+}$-dependent PfHRP2 cytotoxicity. (A) Protective 671 effects of EDTA/EGTA on PfHRP2 cytotoxicity in HT1080 cells. HT1080 cells were treated with 672 PfHRP2 $(1 \mu \mathrm{M})$ in the presence or absence of EDTA/EGTA $(100 \mu \mathrm{M})$ at $37^{\circ} \mathrm{C}$ for $24 \mathrm{~h}$. Relative cell

673 viability was determined using the Cell Counting Kit-8 reaction solution. (B) Binding of PfHRP2 and $674 \mathrm{Ca}^{2+}$ ions. The PfHRP2 $(10 \mu \mathrm{M})$ was incubated in the Eagle's minimal essential medium containing $675 \mathrm{CaCl}_{2}(200 \mathrm{mg} / \mathrm{L})$ with/without EDTA $(100 \mu \mathrm{M})$ at $37^{\circ} \mathrm{C}$ for $1 \mathrm{~h} . \mathrm{Ca}^{2+}$ ion bound to the PfHRP2 was 676 collected using anti-FLAG antibody-immobilized resin. Amounts of collected $\mathrm{Ca}^{2+}$ ions were 677 determined using a Metallo Assay LS Trace Metal Assay Kit for calcium. (C) $\mathrm{Ca}^{2+}$-dependent 678 cytotoxicity of PfHRP2 in HT1080 cells. HT1080 cells were treated with PfHRP2 $(1 \mu \mathrm{M})$ in the 
679 modified medium containing various concentrations of $\mathrm{Ca}^{2+}(0-100 \mathrm{mg} / \mathrm{L})$ at $37^{\circ} \mathrm{C}$ for $24 \mathrm{~h}$. Relative 680 cell viability was determined using the Cell Counting Kit-8 reaction solution. $(D)$ Increase of 681 lysosomal $\mathrm{Ca}^{2+}$ by PfHRP2 and $(E)$ inhibitory effect of EDTA in HT1080 cells. HT1080 cells were 682 treated with various concentrations of PfHRP2 $(0.1-1.0 \mu \mathrm{M})$ with or without EDTA $(100 \mu \mathrm{M})$ at $37^{\circ} \mathrm{C}$ 683 for $24 \mathrm{~h}$. Lysosomal $\mathrm{Ca}^{2+}$ were stained with Cal520-Dextran (MW 10,000), a lysosomal $\mathrm{Ca}^{2+}$ 684 specific fluorescent indicator, and then relative lysosomal $\mathrm{Ca}^{2+}$ levels were determined by 685 measuring MFI in the flow cytometric analysis. Means and SD are shown $\left({ }^{*} p<0.05\right.$ and $\left.{ }^{* *} p<0.01\right)$. 686 n.s. indicates a nonsignificant difference. 


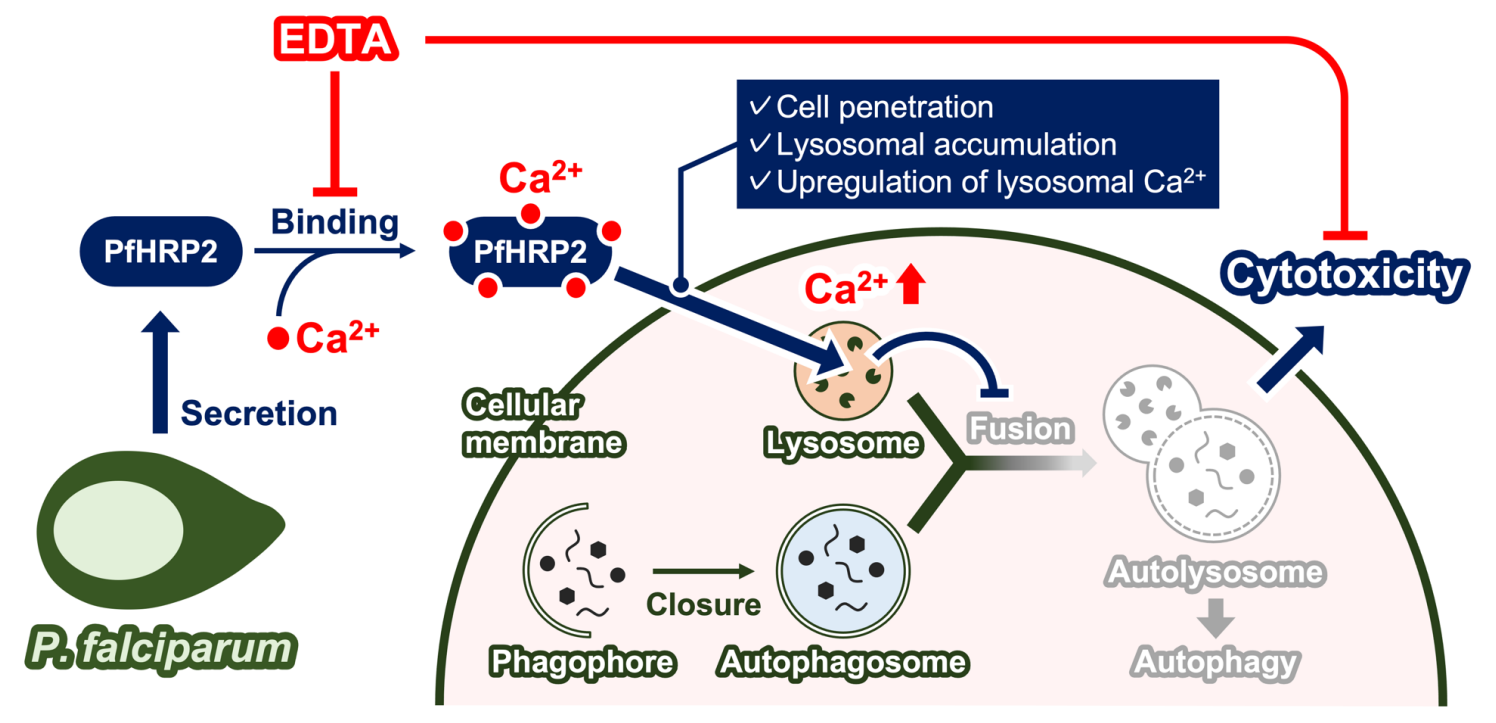

687 Fig. 7. A model for the pathogenic and protective mechanisms of PfHRP2 and EDTA. Plasmodium

688 falciparum secretes PfHRP2 to the bloodstream in P. falciparum-malaria patients. The secreted

689 PfHRP2 binds to $\mathrm{Ca}^{2+}$ ions and penetrates the cell membrane. After cell penetration, the PfHRP2

690 with $\mathrm{Ca}^{2+}$ accumulates to the lysosome, and the lysosomal $\mathrm{Ca}^{2+}$ level increases. Lysosomal $\mathrm{Ca}^{2+}$

691 homeostasis is disturbed by PfHRP2 and lysosome-autophagosome fusion is inhibited. Finally,

692 autolysosome formation, essential for the basal autophagy that maintains cellular metabolism, is

693 also suppressed and cellular proliferation is inhibited. However, EDTA inhibits the binding between

694 PfHRP2 and $\mathrm{Ca}^{2+}$ ions. Thus, EDTA also inhibits the increase of lysosomal $\mathrm{Ca}^{2+}$ levels and 695 subsequent cytotoxicity. 


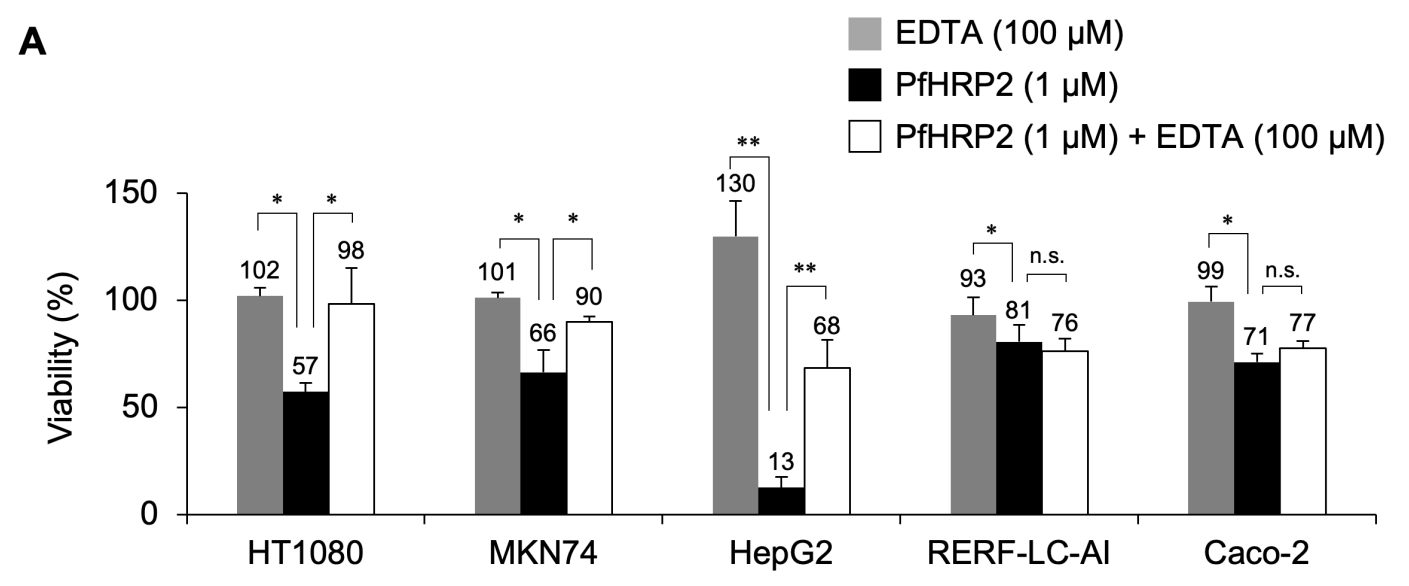

B

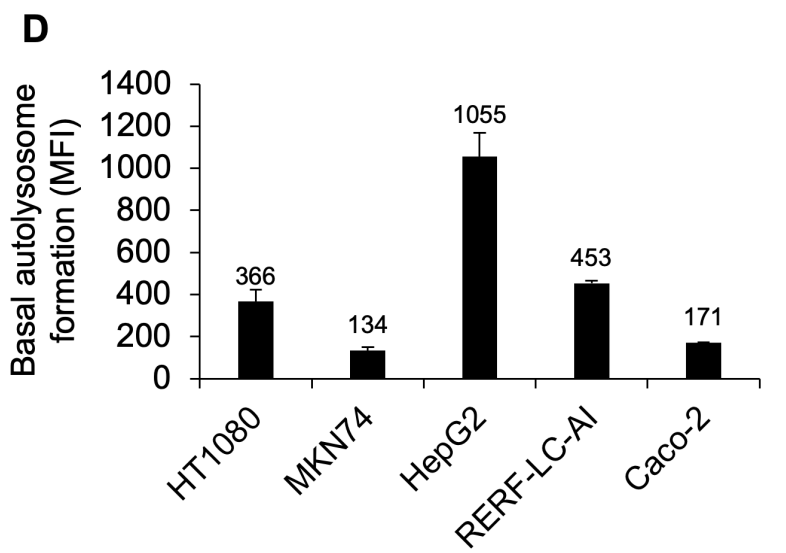

C
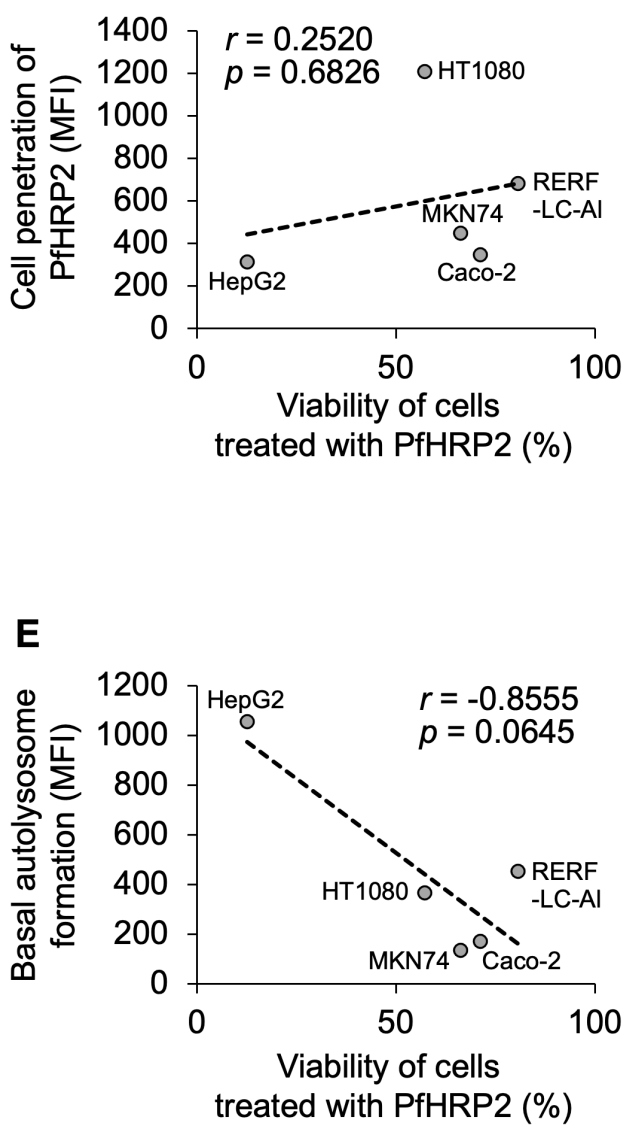

Fig. 8. PfHRP2 pathogenicity and the protective effect of EDTA in various human cells. (A) PfHRP2 
697 cytotoxicity and protective effect of EDTA in various human cells. Cells were treated with PfHRP2 $698(1 \mu \mathrm{M})$ in the presence or absence of EDTA $(100 \mu \mathrm{M})$ at $37^{\circ} \mathrm{C}$ for $24 \mathrm{~h}$. Relative cell viability was 699 determined using the Cell Counting Kit-8 reaction solution. (B) Cellular uptake of PfHRP2 in various 700 human cells. Cells were treated with the Fluo-PfHRP2 $(1 \mu \mathrm{M})$ and Fluo-BSA $(1 \mu \mathrm{M})$ at $37^{\circ} \mathrm{C}$ for 3

701 h. Cell penetration of proteins was evaluated by mean fluorescent intensity (MFI) in the flow 702 cytometric analysis. (C) Correlated distribution between PfHRP2 cytotoxicity and cell penetration. 703 The $X$-axis indicates relative the viability of cells treated with PfHRP2 (\%), see Fig. 8A, whereas 704 the Y-axis indicates cell penetration of PfHRP2 (MFI), see Fig. 8B. $r$ indicates the Pearson's 705 coefficient of correlation. (D) Basal autolysosome formation in various human cells. Cellular 706 autolysosomes were stained with DAL Green and autolysosome formation was determined by MFI 707 in the flow cytometric analysis. (E) Correlated distribution between PfHRP2 cytotoxicity and basal 708 autophagy level. The $\mathrm{X}$-axis is the same as in $C$, whereas the $\mathrm{Y}$-axis indicates basal autolysosome 709 formation, see Fig. 8D. r indicates the Pearson's correlation coefficient. Means and SD are shown $710 \quad\left({ }^{*} p<0.05\right.$ and $\left.{ }^{* *} p<0.01\right)$. n.s. indicates a nonsignificant difference. Cell lines: HT1080, human 711 fibrosarcoma cells; MKN74, human gastric cancer cells; HepG2, human hepatoma cells; RERF712 LC-Al, human squamous lung cancer cells; and Caco-2, human colon carcinoma cells. 